\title{
Reframing Remembrance: \\ A Case Study on Collective Memory in Far-Right Party Discourse
}

by

Lucas Anderson

A thesis submitted to the Faculty of Graduate and Postdoctoral Affairs in partial fulfillment of the requirements for the degree of

Master of Arts

in

Political Science

Carleton University

Ottawa, Ontario

(C) 2019, Lucas Anderson 


\begin{abstract}
The recent success of Alternative für Deutschland in the 2017 German federal election came as a resounding shock to politicians, pundits, and the public alike. As the official opposition, one of the most pernicious aspects of their rhetoric has been their virulent criticism of memory culture which has emboldened fascist groups across the country. Yet it appears as though AfD does not engage in the same overtly revisionist discourse which often sent its predecessors to their demise. This begs an interesting question: how do contemporary far-right parties reconcile their positive association with history in countries with problematic pasts? While there has been a wealth of scholarship on cultural backlash in contemporary far-right populism, existing theories pay little attention to the role of history in far-right discourse despite its growing salience in the public discourses across Europe. Consequently, this thesis seeks to assess the viability of constructing a historical dimension to existing theories on cultural backlash by examining the programmatic usage of references to history in the supply-side far-right party strategy. This is accomplished through an exploratory comparative case study of the electoral programs of farright parties in Austria and Germany which examines far-right parties have adapted their references to history to appeal to contemporary voters.
\end{abstract}




\section{Acknowledgements}

First and foremost, I would like to thank my parents, Mark and Mirian Anderson, for their unwavering support in the face of this monumental task. Their love, care, and encouragement have not only given me the strength to complete this work of scholarship but the conviction to pursue of my dream of pursuing a career in academia. Within the academy I would also like to thank Patricia Fagan and Max Nelson for their academic mentorship and helpful advice over the past two years despite my decision to turn to the "dark side" that is political science; Achim Hurrelmann for his support over the past two years and for first noticing my scholarly potential; James Bowden for his uncanny ability to translate my mad rantings into some semblance of scholarship and finally, my dear colleagues Douglas Fergusson and Alexandra Dauncey-Elwood, without whom this homesick working-class kid from Windsor would never have made it through graduate school. 


\section{Table of Contents}

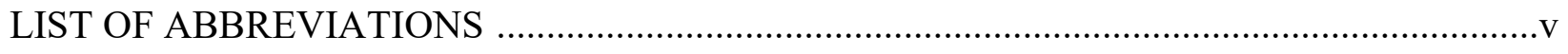

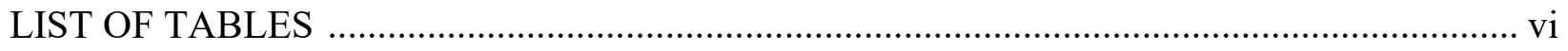

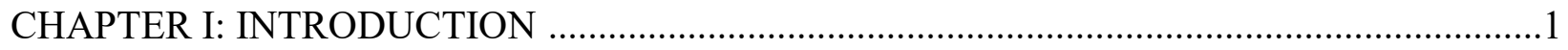

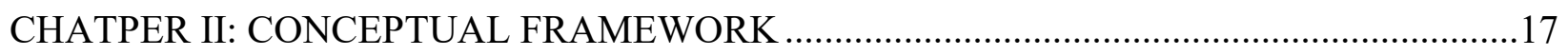

Defining Collective Memory …………………………..............................................18

The Substantive Case for Collective Memory …………………………....................25

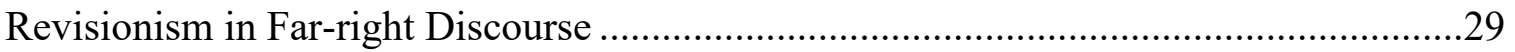

Reframing Strategies in Far-right Discourse ……………….........................................30

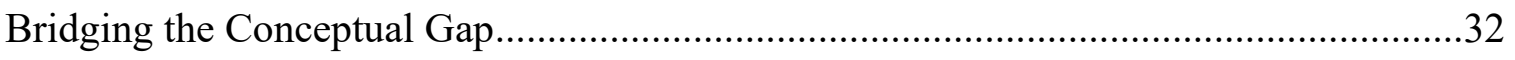

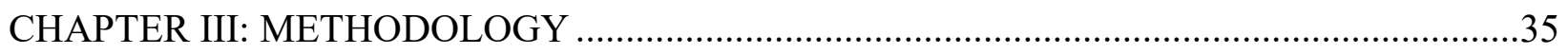

The Trials and Tribulations of Memory Studies...............................................................36

Collective Memory in Far-right Party Scholarship...........................................................39

Collective Memory in Critical Discourse Analysis ........................................................43

Bridging the Methodological Gap ...............................................................................46

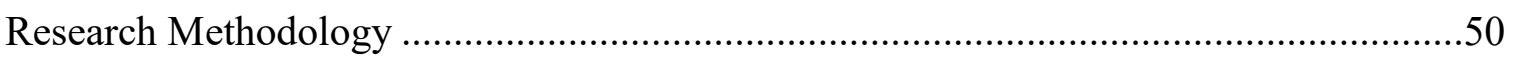

Applying the Discourse-Historical Approach.....................................................50

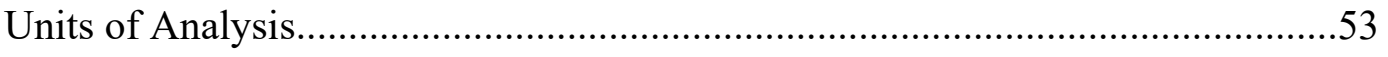

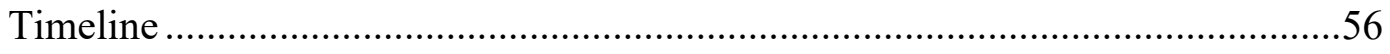

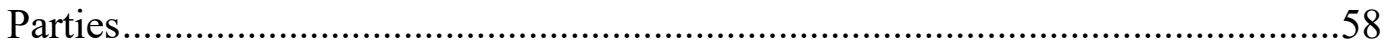

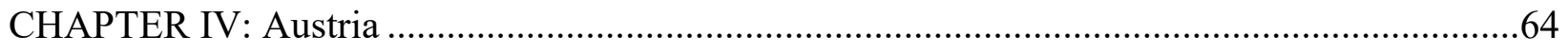

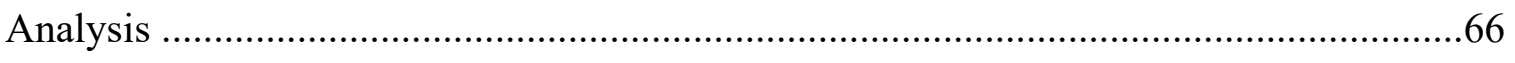

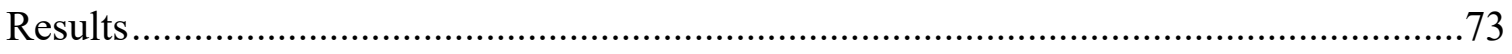

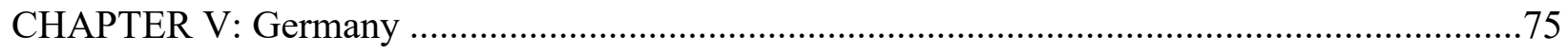

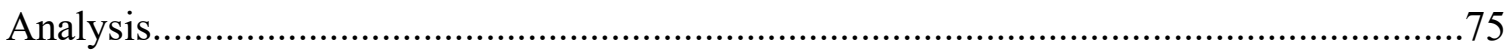

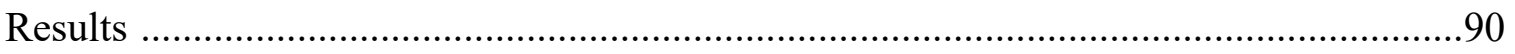

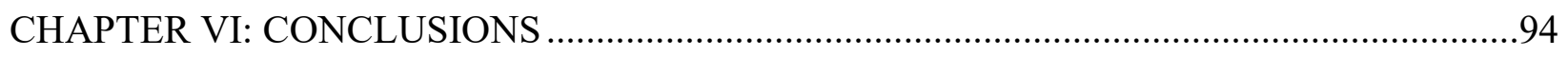

Assessing the Research Question..................................................................................94

Suggestions for Future Research ...............................................................................101

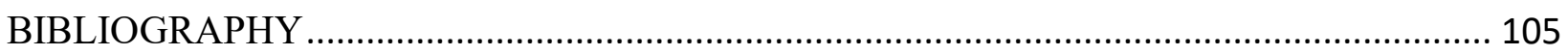




\section{LIST OF ABBREVIATIONS}

$\begin{array}{ll}\text { AfD } & \text { Alternative for Germany } \\ \text { BZÖ } & \text { Alliance for the Future of Austria } \\ \text { CDA } & \text { Critical Discourse Analysis } \\ \text { CDU } & \text { Christian Democratic Union of Germany } \\ \text { CSU } & \text { Christian Social Union in Bavaria } \\ \text { DHA } & \text { Discourse-Historical Approach } \\ \text { DVU } & \text { German People's Union } \\ \text { EU } & \text { European Union } \\ \text { FPÖ } & \text { Freedom Party of Austria } \\ \text { FRG } & \text { Federal Republic of Germany } \\ \text { GDR } & \text { German Democratic Republic } \\ \text { MSSD } & \text { Most Similar Systems Design } \\ \text { NPD } & \text { National Democratic Party of Germany } \\ \text { ÖVP } & \text { Austrian People's Party } \\ \text { REP } & \text { The Republicans } \\ \text { UN } & \text { United Nations } \\ \end{array}$




\section{LIST OF TABLES}

Table 1 - List of Textual Materials for Content Analysis ..................................................61 


\section{I: Introduction}

The recent electoral success of Alternative für Deutschland (AfD) in the 2017 German Federal election came as a resounding shock to politicians, pundits, and the public alike. While the rest of Europe has struggled with far-right populist forces, Germany had long stood resolute, acting as the last great bulwark holding back the torrent of racism, xenophobia, and nationalism engulfing the European continent. This situation arose not by circumstance, however, but is the product of Germany's long and complex relationship with its far-right past. As the guns of the Second World War fell silent and the scars wrought by Nazism were laid bare, Germany began the arduous process of Vergangenheitsbewältigung (working through the past) which advocated public reconciliation for their complicity in the crimes of the Nazi regime. It was a process fraught with difficulty as many Germans were unwilling to accept collective responsibility for the actions of the Nazi regime and it was not until the 1960s and 70s that generational change caused a significant shift in attitudes towards collective and led a significant number of Germans to favour a reckoning with their traumatic past. ${ }^{1}$

By the early 1980s, grassroots activism had built a vibrant culture of memory which actively encouraged Germans to critically engage with their traumatic history. ${ }^{2}$ The growing cultural significance of collective memory soon extended to the political domain where the advent of Geschichtspolitik (memory politics) facilitated the a long tradition of active reconciliation into the foundation of political discourse. The advent of memory politics led to the

\footnotetext{
${ }^{1}$ Jeffery Herf. Divided Memory - The Nazi Past in the Two Germanys. (Cambridge: Harvard University Press, 1997).

${ }^{2}$ Wüstenberg, Jenny and Art, David. "Using the Past in the Nazi Successor States from 1945 to the Present," The Annals of the American Academy of Political and Social Science 617, No. 1 (2008) 72
} 
establishment of a set of cultural norms which extended beyond the realm of activism and came to define the very core of cultural identity in modern Germany. ${ }^{3}$ The influence of memory culture would, over time, be lauded as a model from which developed countries could base their own processes of reconciliation. In the eyes of many, Germany was one of the few countries which was willing to face its past, admit its failings, and hold itself accountable for its actions. From an academic perspective, the significance of memory in both the cultural and political foundation of Germany led to the development of a rigorous body of interdisciplinary scholarship on the subject and remains a subject of intense interest across many disciplines. ${ }^{4}$ While not all Germans shared this view, the prevalence of memory culture in political, social, and academic sphere demonstrates its cultural dominance in contemporary German society.

It is the prevalence of this vibrant memory culture that makes the recent resurgence of the German far-right all the more interesting as a subject of scholarly research. When the populist wave first swept over Europe, it appeared that the very ethos of memory culture was facing its penultimate test. Germany's resistance to the allure of the far-right seemed to validate decades of painful reconciliations with not only its Nazi past, but the profound cultural developments in social justice, the recognition of marginalized groups and reconciliation of Germany's colonial past all of which owe their place in cultural discourse to the prevalence of memory culture. ${ }^{5}$ However, the assumption that Germany would resist the allure of populism proved to be premature. Lurking in the shadows of Germany’s cultural reckoning was a growing sense of resentment among those left behind by the profound political, cultural, and economic changes

\footnotetext{
${ }^{3}$ Ian Buruma. The Wages of Guilt: Memories of War in Germany and Japan (New York: New York Review of Books, 2015) 17-18

${ }^{4}$ Eric Langenbacher and Friederike Eigler. "Memory Boom or Memory Fatigue in $21^{\text {st }}$ Century Germany," German Politics and Society 76, Vol. 23, No. 3 (Fall 2005): 1-15

${ }^{5}$ Chris Weedon and Glenn Jordan. "Collective Memory: Theory and Politics," Social Semiotics 22, No.2 (April 2012) 144
} 
that have shaped modern society. Marginalized and underrepresented, the anger of this growing minority soon coalesced into an anti-establishment counterculture which soundly rejects the current set of cultural norms that memory politics has helped create. These views are born from the assertion that the primacy of the nation state and, by extension, the preservation of that nation's culture and history is the only panacea to the issues wrought by encroaching globalization, cosmopolitization and demographic change. Shunned by mainstream political parties and yearning for political representation, this counterculture has ushered in the unthinkable, a return to far-right politics.

AfD changed everything. What began as an obscure group of disgruntled fiscal conservatives had evolved into a full-fledged far-right political party with significant resources and platform of nationalist, identitarian, and anti-immigration policies. ${ }^{6}$ Their stunning electoral success in the 2017 Federal Election, which saw them win $12.6 \%$ of the vote and 94 seats in the Bundestag, catapulted them from the fringes to the forefront of German politics. While far-right parties had always attempted to attain a degree of cultural hegemony in the public sphere, AfD's unprecedented success and newfound position as the largest opposition party in the Bundestag has significantly changed the dynamic by giving them a prominent public platform to advocate for radical shifts in cultural thought.

In the past, AfD has often expressed its animosity towards the existing culture of memory but it has quickly evolved into one of the most pernicious aspects of their rhetoric. Through several controversial statements, speeches, and writings many of which denounce established norms of remembrance as a "culture of guilt," AfD has positioned itself as a meaningful

\footnotetext{
${ }^{6}$ Frank Decker. "The 'Alternative for Germany' Factors Behind its Emergence and Profile of a New Right-wing Populist Party," German Politics and Society 119, Vol. 34, No.2 (Summer 2016): 1-16
} 
alternative to not only mainstream political parties but mainstream cultural perspectives as well. Most recently, their attempts to influence these cultural norms has moved from discourse to action. Aside from a number of controversial speeches, AfD has attacked cultural and educational institutions in the form of high-profile lawsuits and spearheaded various political advertising campaigns which break established taboos. ${ }^{7}$ Some scholars of German politics have noted that the success of AfD has sparked a 'culture war' in which the far-right has utilized their position chip away at Germany's cultural norms in order to establish their own cultural hegemony. ${ }^{8}$ While the exact nature of this cultural contestation and the related discourse are still the subject of ongoing research, it is becoming increasingly clear that the far-right's struggle for cultural hegemony has been aided, at least in part, by the operationalization of history, identity, and culture by the far-right.

Opposition to post-war consensus of history is not a new phenomenon in Germany, but the key difference lies in AfD's willingness to break established taboos which represents an unprecedent shift in mainstream political discourse. This situation is particularly problematic due to the specific historical connotations of Germany's past which make the appeal to nationalism all the more troubling in a contemporary context. Some notable examples of this phenomenon include Björn Höcke’s declaration that Berlin's Holocaust memorial was a “monument of shame" and his subsequent call for all Germans to make a "180-degree turn" in the "laughable" policy of coming to terms with the past. ${ }^{9}$ In a more recent condemnation of Germany's memory

\footnotetext{
${ }^{7}$ Stuart Braun. “As Far-Right Culture War Escalates in Germany, Concerns Grow." The Wire, June $2^{\text {nd }}, 2019$. Accessed June $17^{\text {th }}$, 2019. [https://thewire.in/world/as-the-far-right-culture-war-escalates-in-germany-concernsgrow]

${ }^{8}$ Samuel Salzborn "Renaissance of the New Right in Germany?" German Politics and Society 119, 34, No. 2 (Summer 2016) 36-37

${ }^{9}$ Lizzie Dearden. "German AfD politician 'attacks Holocaust Memorial' and says Germany Should be more Positive About its Past." Independent, January 19 th 2017. Accessed August 9", 2019
} 
culture, AfD co-leader Alexander Gauland's claimed that the Nazi era was a "speck of bird poop" in the nation's long history. ${ }^{10}$ Other incidents have included the use of Nazi-era terminology such as volk and völkisch which, despite their Nazi connotations, have been used frequently by AfD politicians including Frauke Petry, Alexander Gauland, and Björn Höcke. ${ }^{11}$ Moreover, Saxony-Anhalt AfD leader Andre Poggenburg has often evoked racially tinged Naziera terminology in reference to marginalized groups. ${ }^{12}$ Virulent criticism from opposition politicians, activist groups, and the large swaths of the public, done little to assuage these statements and, if these trends continue, the institutionalization of far-right parties through electoral success could herald a shift in the cultural discourse, memory culture and the political significance of memory as a whole.

Germany's struggle to reconcile its troubled past with the insidious historical rhetoric of resurgent far-right parties poses an interesting question that may have broader implications for scholarly research: What happens when the far-right's positive association with history coincides with a problematic past? Once thought defeated by the triumph of Liberalism, the turbulent political climate of the past decade has been punctuated with a form of nationalistic populism which is largely based on appeals to culture, identity, and tradition. But what happens when these appeals go to far? What happens when they legitimize hate or inspire violence? Or when they threaten to tear down the progress of decades of reconciliation? The consequences of this phenomenon are already being felt in Germany as far-right protests rage, Nazi flags are flown

\footnotetext{
${ }^{10}$ Karin Laub. "AfD Chief: Nazi Era a 'Speck of Bird Poop' in German History." AP News. June $2^{\text {nd }}, 2018$. Accessed August $9^{\text {th }}, 2019$. [https://www.apnews.com/35a927e3ae954fa386a9e2406ae4439a]

${ }^{11}$ BBC News “Nazi Word Revived by German AfD Chief." September 12, 2016. Accessed June 29 2019. [https://www.bbc.com/news/world-europe-37337927]

${ }^{12}$ Stuart Braun. "As Far-Right Culture War Escalates in Germany, Concerns Grow." The Wire, June $2^{\text {nd }}, 2019$. Accessed June $17^{\text {th }}$, 2019. [https://thewire.in/world/as-the-far-right-culture-war-escalates-in-germany-concernsgrow]
} 
openly, and refugees fleeing oppression are assaulted in the streets. Consequently, this thesis has chosen to set its research focus on this subject with the goal of understanding the historical aspects of far-right discourse.

Considering the recent political developments in Germany, it is clear that far-right parties are becoming increasingly emboldened with respect to references to history, but the question remains as to what separates them from previously unsuccessful far-right parties, many of whom also made nationalistic references to history. This thesis proposes an initial hypothesis which argues that contemporary far-right parties have shifted towards discursive strategies which seek to reframe a society's collective memory instead of engaging in revisionism. This reframing involves utilizing references to history in ways which enable them to avoid the negative connotations of in their respective countries while utilizing them to further their populist and nationalist messaging. This hypothesis will serve as the basis for much of the proceeding study and will be tested by the research work of this thesis.

In order to fully understand this discursive shift, the larger context of far-right politics and test the established hypothesis, a research approach must be developed which widens perspective of this concept beyond the bounds of Germany. It is clear from the recent success of similar far-right rhetoric in other countries that this more than a quirk of Germany's memory culture and represents a more profound phenomenon. The wide scope of contemporary far-right politics lends itself to comparative analysis which would both provide insight into far-right discursive techniques in general and evaluate the differences in their application across countries and over time. Fortunately, there is a country which shares a language, culture, and troubled relationship with the nation, Austria, a country that has adopted an approach to memory which thought to be the complete opposite of Germany's robust memory culture. 
In contrast to Germany's robust memory culture, Austria established a contrasting societal consensus on collective memory which sought to absolve the country of its involvement in the crimes of the Nazism. Austria's desire for exculpation was first reflected in the Austrian Declaration of Independence of 1945 which specifically states that Austria was "Hitler's first victim," a concept conveniently cherry-picked from the Moscow Declaration of 1943. The concept of Austria as a victim of Nazism permeated their political culture creating an institutionally engrained ambivalence to collective memory which evolved into a societal taboo. Much like early post-war Germany, Austrians were generally unwilling to accept collective responsibility for the crimes of Nazism and argued that they were the victims. However, the intergenerational shift which initiated the rise of German memory culture failed to take shape in Austria due to the insulating influence of the "great taboo." After 40 years of silence, the memory debate was reignited by the raucous public debates of the Waldheim Affair of 1986 in which Austrian People's Party (ÖVP) presidential candidate Kurt Waldheim was accused of covering up his Nazi past. While these events did not inspire any major shifts in the memory debate, it did inspire a small active group of scholars to produce scholarly research on Austria's Nazi past and became the first advocates for a more critical approach to collective memory in Austria. $^{13}$

The memory debate and references to history in general remained largely dormant in Austria until the rise of the Austrian Freedom Party (FPÖ) in the late 1990s. While it had long persisted as FPÖ shifted towards a far-right populist party led by Jörg Haider, a controversial ultraconservative politician who openly expressed nationalist views, and frequently made controversial statements which painted Austria's involvement with Nazism in a positive light. In

\footnotetext{
${ }^{13}$ Wüstenberg and Art 79
} 
2000, a general election led to the formation of a coalition between the ÖVP and FPÖ under the leadership of Wolfgang Schüssel. Although Haider was not offered a cabinet position, the ÖVP's willingness to govern with Haider's party was harshly criticized by many members of the European Union (EU) who imposed diplomatic sanctions on Austria. ${ }^{14}$ While Haider would eventually leave FPÖ after a string of electoral failures, the party endured under the leadership of Heinz-Christian Strache who, despite his claims to the contrary, continued to utilize this rhetoric in a subtler way which preys upon modern struggle with identity, culture, and tradition. ${ }^{15}$

A similar situation has emerged in 2017, as another ÖVP- FPÖ coalition was formed under the leadership of Sebastian Kurz. While the political response to the FPÖ's position has been relatively toothless, they have been subjected to a significant level of domestic criticism which is unprecedented in Austrian politics. Since their ascension to government, the FPÖ has been embroiled in several scandals involving controversial statements by party officials. These statements ranged from slights against migrants to praise for Nazism, racism, and antisemitism. This has resulted in significant public backlash including large protests and, much like AfD, the resignations of high-ranking officials. In response to this controversy, FPÖ parliamentary leader Walter Rosenkranz agreed that some criticism of these statements was "justified" and agreed that the party had a "special responsibility" to explore the issue as a partner in the government. ${ }^{16}$ The

\footnotetext{
${ }^{14}$ Wüstenberg and Art 80

${ }^{15}$ Ruth Wodak. "Anything Goes!" - The Haiderization of Europe" in Right-Wing Populism in Europe: Politics and Discourse eds. Ruth Wodak, Majid Khosravinik, and Brigitte Mral (London: Bloomsbury Academic, 2013) 25-26 ${ }^{16}$ Patrick Strickland. “Is Austria's Far-Right FPÖ Losing Support Amid Nazi Scandals?” Aljazeera. April 2, 2018. https://www.aljazeera.com/news/2018/03/austria-fpo-losing-support-nazi-scandals-180331101800263.html Accessed October 9th, 2018.
} 
party has since ordered the creation of a historical commission to investigate and evaluate its associations with Nazism which is still ongoing. ${ }^{17}$

While these developments may seem to indicate a promising trend in a country that has long spurned the idea of memory culture, many scholars have been quick to point out that farright discourse still has a significant foothold in Austrian society albeit through different avenues. Haider's influence on political discourse led to the establishment of a new set of discursive norms facilitating increasingly discriminatory language and a surge in nationalistic rhetoric which has been the object of intensive study. Moreover, the growing presence of "othering" in public discourse has led to the propagation of overt expression of Islamophobia political writings, discourse, and media. ${ }^{18}$ With the recent collapse of Sebastian Kurz's coalition government, these developments will most likely be thrown into disarray and it is evident that collective memory could play an increasingly important role in Austrian politics. What role will memory play in the upcoming elections remains to be seen but it is clear that warrants further analysis both comparatively and in the context of the contemporary far-right.

Despite their contrasting approaches to memory, and some key differences in the nature of far-right parties in both countries, it is clear from this initial comparison that the references to history are also utilized in far-right discourse in Austria. The similarities in culture, language, and history present an interesting opportunity allow for the development of a comparative research approach based on Most Similar System Design. This thesis will seek to compare Germany to Austria, with Austria serving as a model due to its similar history and earlier far-

\footnotetext{
17 Jon Stone. "Austria's Far-right Party FPÖ says Criticism of its Nazi Links is justified," Independent. February 16, 2018. https://www.independent.co.uk/news/world/europe/fpo-far-right-nazi-links-justified-heinz-christianstrache-austria-a8214086.html Accessed October 9th, 2018. ${ }^{18}$ Ruth Wodak and Bernhard Forchtner. "Embattled Vienna 1683/2010: Right-wing Populism, Collective memory and the Fictionalisation of Politics," Visual Communication 13, No. 2 (2014) 233
} 
right success. This comparison would not only test the hypothesis established above by assessing the discursive techniques of both parties but analyze whether Germany has become more like Austria or if it is part of a new trend in far-right discourse. The shared history and contrasting approaches of these two countries in particular allows for the reduction of external variables which would make other cross-national comparisons of collective memory difficult to reconcile.

With respect to the cultural implications of far-right references to history, it appears that in a rapidly changing world buffeted by globalization and cosmopolitanism, some have adopted the view that history, culture, and tradition as the only constant in a rapidly changing cultural landscape. It is no wonder that there has been a marked increase in references to history and significant shifts in focus of far-discourse as it presents the far-right with an established pretext for legitimizing their views and justifying their actions. The insights gained from this exercise in comparative analysis demonstrate that there is significant research potential in studying references to history in far-right discourse and, from this point forward, it will be the primary focus of this thesis.

The enigmatic nature of contemporary far-right parties in the rapidly shifting cultural landscape of contemporary society has led to the propagation of a wide array of unanswered questions within the existing literature as scholars struggle to understand them. Scholars are still working through questions such as: How are these far-right movements different from those in the past? What about them is different and in what ways? And, why have they been successful in some countries and not others? The existing body of literature reveals that scholars are working to decipher a number of unexplained aspects of far-right discourse: Whom do far-right parties address with their rhetoric and how? What kinds of rhetoric, slogans, and arguments do they use? And what is their relationship to culture, identity, and history? The lack of scholarship will 
undoubtedly pose a challenge, but it also presents an unprecedented opportunity for this thesis to contribute to efforts to make sense of far-right politics. Consequently, it is in the gap in existing research on far-right discourse described above that this thesis will be situated and seek to make its contribution by examining the significance of history.

It is clear, from the events described above, that any effort to interpret the far-right's relationship to history must begin with a thorough understanding of its cultural appeals to national identity and their significance in the context of contemporary society. So how does one begin to understand the complex backdrop of cultural contestation that drives the historical aspects of far-right discourse? The existing body of theory on contemporary far-right populism provides some insight in this respect with cultural backlash theory providing the most pertinent framework. The term cultural backlash was first coined by Ronald Inglehart in his works on post-material theory. In his book The Silent Revolution, Inglehart argued that the existential security of the post-war period inspired a shift from material to post-material values such as multiculturalism, cosmopolitanism and gender equality which inspired subsequent generations to trend towards progressivism. Inglehart's theory has been corroborated by a large body of survey research which confirmed both an intergenerational shift in value priorities and a growth in the number of 'progressive' social movements based on cultural and social issues. ${ }^{19}$ This significant shift in values has elicited a hostile reaction from older traditionalists whose opposition to progressivism translated to antagonistic political action and the exacerbation of existing divisions of age, gender, and education. ${ }^{20}$

\footnotetext{
${ }^{19}$ Ronald Inglehart. "Changing Values Among Western Publics, 1970-2006: Post-Materialist Values and the Shift from Survival Values to Self-Expression Values," West European Politics 31(1-2), (2008): 132

${ }^{20}$ Ronald Inglehart and Pippa Norris. "Trump, Brexit, and the Rise of Populism: Economic Have-nots and Cultural Backlash," HKS Faculty Research Working Paper Series, RWP16-026 (August 2016) 3-4
} 
Inglehart argues that the polarization of cultural conflict along the "traditionalist vs. progressive" divide and the creation of an "us vs. them" mentality has served as one of the catalysts for the resurgence of far-right politics. Cultural backlash theory addresses this phenomenon by asserting that the nature of contemporary far-right populism is based on a counter-revolutionary backlash from previously dominant cultural groups who reject the value change of post-materialism and yearn for strong leadership that will usher in a return to traditional values, and adherence to the norms established by the cultural majority.

Consequently, this thesis will seek to understand how far-right parties communicate those goals through references to history and the discursive techniques they utilize.

Ronald Inglehart and Pippa Norris conducted extensive work on cultural backlash culminating in a large-scale study on the 'demand-side' dynamics of the modern populist right which sought to determine whether economic or cultural factors are the primary drivers of party support in developed nations. Using multivariate regression analysis of European Social Survey Data, Inglehart and Norris examined cross-national evidence at the individual level for the impact of economic insecurity and cultural values as indicators for populist party support. The study revealed that the cultural backlash theory provided the most consistent evidence for populist party support while the results for the economic theories were mixed and variable. Although Inglehart and Norris note that the economic and cultural factors are not mutually exclusive, they concluded that cultural factors are more likely indicators of populist support. ${ }^{21}$

The implications of this recent research are profound as they provide a firm foundation for the prospective research focus of this thesis. The present public desire for political

\footnotetext{
${ }^{21}$ Inglehart and Norris, 45-46
} 
representation which espouses the ideas expressed by cultural backlash has undoubtedly had a profound effect on the political dynamics of many countries and the newfound emphasis on culture warrants further research especially on the supply-side which is somewhat underdeveloped from the perspective of cultural backlash. If there is a considerable demand-side evidence for the types of cultural platforms described by Inglehart and Norris, it is only natural that far-right parties have either had a role in establishing or have adapted their strategy. The recent propagation of historical references in their discourse thus provides an ample opportunity for applicable supply-side research.

Building within the larger framework of the cultural backlash theory, this thesis will examine the 'supply-side' of far-right party strategy with the aim of adding a historical dimension to existing cultural theories on the cultural appeal of far-right discourse. The impetus for this research is derived from Inglehart and Norris' assertion that the process by which farright parties attract traditionalist voters is based on the presentation of a nostalgic national ideal. They argue that, in order to attract traditionalist voters, far-right parties generally present a cultural vision for the country which harkens back to a 'golden era' in a nation's past when the cultural predominance and social values of traditionalists were secure. ${ }^{22}$ By constructing a historical narrative that stands in opposition to progressivism, far-right parties can easily present themselves as a viable outlet to express cultural backlash and protect national identity. Consequently, it can be argued that cultural backlash against value change can be expected to be associated with positive reference to the past which is evident throughout the rhetoric of far-right leaders across the developed world. However, these nostalgic yearnings become increasingly problematic in countries with traumatic pasts where nostalgic yearnings are directly associated

\footnotetext{
22 Inglehart and Norris, 16
} 
with violence, tyranny, and oppression. This is particularly relevant in Europe in which the vast and many countries bear the scars of communism, fascism, and sectarian violence over the course of their histories.

There are, however, a number of challenges that come with conducting research on the use of history in a social context. As an object of political analysis, history must be conceptualized not as a static phenomenon but a fluid concept which is highly influenced by ideational factors such as culture, perception, and identity. Aside from the challenge of establishing conceptual boundaries, it should be noted that scholars must also account for the individual and societal effects of memory which acts as the medium through which history is both interpreted and applied to actions. While scholars have long argued that these issues have led to a relatively underdeveloped understanding of the causal mechanisms of history and memory in political science, there has been significant progress in the field as a whole in the past especially in the European context. Consequently, there is a wide variety of research on the political role of history which will both serve as the foundation of this thesis and dictate its course as it is adapted to address contemporary struggles with cultural backlash. ${ }^{23}$

This thesis will seek to build on both cultural backlash theory and the existing research on memory in politics by analyzing references to history in far-right discourse through the sociological lens of collective memory. Collective memory, which conceptualizes history as a shared pool of memories, knowledge, and information of related to a social group's identity, provides a flexible conceptual basis which accounts for the "active" nature of history the political context of far-right discourse. While there are challenges tied to the application of collective

\footnotetext{
${ }^{23}$ Wüstenberg and Art 82-83
} 
memory in political science, its conceptual basis provides a compelling means for understanding the significance of history in far-right discourse and could provide a more nuanced set of findings with respect to cultural backlash theory by clearly demonstrating the role of history and memory in its function.

In practice, this thesis proposes an exploratory case study which analyzes the use of history by far-right parties. This will consist of a critical discourse analysis of far-right party programs using the discourse-historical approach. The contextual basis of this analysis will be conducted through the sociological lens of collective memory which will serve the contextual basis for its examination of historical references. The research work of this thesis will involve content analysis of how political parties refer to history across countries and over time. Despite its straightforward appearance, the nature of this research question provides the conceptual flexibility needed address a concept like history which is often intertwined with similar social phenomena such as culture, tradition, and national identity.

The primary objectives of this research are threefold. First and foremost, this thesis seeks to develop a detailed account of references to history in far-right discourse outlining their content, meaning, and historical context as well as their relationship to cultural backlash. Second, it will attempt to make a lasting contribution to the scholarship by constructing the foundation for the development of a historical dimension to existing theories on far-right discourse, the workings of far-right party politics, and cultural backlash as a whole. Third, it will assess the significance of history in far-right discourse from a political perspective and apply its findings to the ongoing of instances of cultural contestation occurring within the party systems of Europe. 


\section{Structure of the Thesis}

The structure of the thesis will be organized as follows: Chapters II and III will each consist of systematic literature reviews which address the well-documented conceptual and methodological challenges of working with collective memory, justifies its utility and integrates it into the existing body of research on far-right parties. Chapter II addresses the conceptual aspects of the thesis by connecting the substantive findings of collective memory in political science with current theories on far-right discourse to construct a conceptual framework to address the research question. Chapter III reviews the methodological aspects of the existing literature to determine the best method for studying collective memory, reconciles those methods with current studies on far-right party discourse, and utilizes the findings to inform the construction of the methodological framework for the proposed discourse analysis. Chapters IV and $\mathrm{V}$ present the results of the discourse analysis for Austria and Germany respectively. Within each chapter, a number of key passages will be examined followed by a thorough discussion of the findings across countries over time, and within their current historico-cultural context. Finally, Chapter VI will reconcile the findings of the analysis with the goals of the research question, discuss the findings of the analysis within the broader context of the existing scholarship, and making suggestions for future research. 


\section{II: Conceptual Framework}

"The control of memory is a form of power. Persons in a position to manipulate memory, and with it the valued symbols of a society or group hold political power." - Herbert Hirsch (1995)

The presence of contentious references to history in far-right party discourse presents an intriguing opportunity for scholarly research, especially in the context of culturally based theories on the rise of far-right populism. Yet the study of discourse alone seems too limited to adequately address the profound cultural changes described in the work of Inglehart and Norris. For it is not simply the references to history themselves which provide insight into the 'supplyside' of cultural backlash but their meaning, their cultural context, and the underlying process of memory which govern them. The truth of this phenomenon lies in understanding how we remember, why we remember, and what those memories mean to society. It is only by addressing these deeper questions that one can construct that historical dimension and truly understand the relationship between history, culture, and the far-right. Consequently, this study will explore the cultural aspects of historically-based far-right discourse by analyzing the research question through the lens of collective memory, a sociological concept which describes the processes of societal remembrance and its role in the construction of national identity. Through engaging with both the discursive aspects of the far-right and the mnemonic processes which drive them, this thesis seeks to provide a more nuanced foundation for a historical dimension to the cultural backlash theory.

The decision to analyze the far-right's programmatic references to history through the lens of collective memory does, however, present its own set of challenges. Collective memory 
is not simply a variable to be measured but a complex sociological concept that must be defined, conceptualized, and integrated into the existing frameworks of political science. The prospect of addressing the research question by studying collective memory thus poses a number of key questions that must be answered through the conceptualization process. How is collective memory defined and where do its conceptual boundaries lie? How does collective memory affect the functions of politics and political discourse? And, perhaps most importantly, how is collective memory connected to recent developments in far-right politics? It is essential that this review address these questions and develop a thorough understanding of the collective memory so that it can be properly integrated into the conceptual and methodological frameworks of this thesis.

With this in mind, the following chapter will consist of a literature review which critically engages with the substantive contributions of the existing body of literature on the farright parties and collective memory to construct a conceptual framework for the application of collective memory. Its will focus primarily on literature pertaining to the state of political discourse in far-right politics while pointing out gaps which this research will address. The primary goal of this review is to present the substantive case for the study of collective memory in far-right party discourse through the creation of a working typology based on the existing literature. This typology will be used to study shifts in far-right discourse and compare similar techniques across both countries both of which will facilitate the research work of this thesis.

\section{Defining Collective Memory}

The key to any piece of social scientific research lies with the definition of its key concepts, subjects, and variables for they play a pivotal role in defining the analytical boundaries 
which allow the scholarly research to be carried out in a consistent and substantive manner. ${ }^{24}$ The study of collective memory presents a particularly difficult task in this respect for it is not one clearly defined variable but a complex sociological concept tied to inexplicit variables such as identity, self-esteem, and collective consciousness. It is a largely implicit concept which is not based on object fact but exists as a "fluid set of ideas" often reshaped by time, emotion, and the politically savvy. ${ }^{25}$ Scholars have often struggled to properly define collective memory due to its conceptual flexibility which has contributed to the propagation of a number of disparate approaches to its definition. In its most basic form, collective memory is defined as a "shared pool of memories, knowledge, and information of a social group that is significantly associated with the group's identity." 26 This definition is functional and does describe the basic premise of collective memory but it fails to capture the conceptual depth required for the rigours of scholarship.

There have been many attempts to define collective memory have often attempted to build on the basic definition by constructing supplementary theory, there is little consensus as to how they fit together into any kind of universal definition of collective memory. There are a number of reasons why collective memory has been notoriously difficult to define in the context of scholarship. Wertsch and Roediger note that despite the vast array of memory scholarship spread across the fields of sociology, anthropology, psychology, history, and political science, there has been relatively little scholarly coordination between disciplines leading to a lack of

\footnotetext{
${ }^{24}$ Peter Verovšek. "Collective Memory, Politics, and the Influence of the Past: The Politics of Memory as a Research Paradigm," Politics, Groups, and Identities 4, No.3 (2016) 535

${ }^{25}$ Zheng Wang. Memory Politics, Identity, and Conflict: Historical Memory as a Variable (London: Palgrave MacMillan, 2018) 2-3

${ }^{26}$ Henry L. Roediger and Magdalena Abel "Collective memory: A New Arena of Cognitive Study". Trends in Cognitive Sciences 19, No.7 (July 2015) 359-361
} 
definitional clarity. ${ }^{27}$ Jack Levy argues that the "isolation" of historical memory within these disciplines has caused their development to be compartmentalized and produced a number of disparate definitions. ${ }^{28}$ Moreover, Peter Verovšek points out that the lack of a unified approach to historical memory has led to a type of "conceptual band-wagoning" in which the growing interest the concept has led to its presence in many studies where it has little to do with the central argument of the research. ${ }^{29}$ These issues have led to the propagation of a large body of disparate definitions of collective memory each tailored to meet the needs of its discipline. It is this definitional disparity which lies at the root of the conceptual issues which plague collective memory and prevented its integration into the existing frameworks of political science.

So how does one begin to define that which has been deemed undefinable? In recent years, most scholars who work with collective memory have adopted a "bottom-up" approach which derives a definition from its sociological roots and builds on them in order to avoid becoming bogged down in the conceptual issues of the existing literature. ${ }^{30}$ These definitions are derived from works of Maurice Halbwachs, whose seminal works On Collective Memory and The Collective Memory are considered to be the conceptual framework for the study of societal remembrance. ${ }^{31}$ While other sociologists of the time focused on the individual nature of memory, Halbwachs adopted a collectivist approach arguing that groups construct memories while individuals act on them. Moreover, he argued that collective memory was a not a natural

\footnotetext{
27 James V. Wertsch and Henry L. Roediger III. "Collective Memory: Conceptual Foundations and Theoretical Approaches," Memory 16, No. 3 (2008) 318

${ }^{28}$ Jack Levy. "Case Studies: Types, Designs, and Logics of Inference," Conflict Management and Peace Science Vol. 25, No. 1 (2008) 1-2

${ }^{29}$ Verovšek 534

${ }^{30}$ Wüstenberg and Art 72-73

${ }^{31}$ Both On Collective Memory (1992) and The Collective Memory (1980) are not individual pieces but collections of Halbwachs' publications from the 1920s, 30s, and 40s which were published posthumously in English after his death in Buchenwald concentration camp in 1945.
} 
phenomenon but a socially constructed concept which was always mediated through a complex process of manipulation by elites and unconscious absorption by the public. ${ }^{32}$ Halbwachs' work on the socially constructed nature of memory led him to suggest that all individual memory was, by nature, constructed within the social structures and institutions of society at large. ${ }^{33}$ These societal constructs shaped the formation of individual memories and acted as the basis for the selection and interpretation of formative events through the establishment of cultural norms. Moreover, Halbwachs concluded that it was impossible to separate individual memory from the influence of society and that every aspect of collective memory is dependent on the individual circumstances of their constituent group.

Perhaps the most important aspect of Halbwachs' work is his development of the "instrumental presentist" framework which acts as the basis for the conceptualization of collective memory. Since he had determined that collective memory is influenced by manipulation of the elite, Halbwachs' natural conclusion was that social constructions of memory are primarily influenced by the needs of the present and will invariably be instrumentalized by the leaders of any given social group. Halbwachs determined "collective memory reconstructs its various recollections to accord with contemporary ideas and preoccupations" and pointed out that the instrumentalism of collective memory is inherently tied to 'present' social, cultural, and political considerations. ${ }^{34}$ This is accomplished through commemoration, interpretation, and sometimes elimination of certain events which are deemed to meet the needs of the present. Moreover, the instrumentalization of collective memory also

\footnotetext{
32 Maurice Halbwachs. On Collective Memory ed. and trans. Lewis A. Coser (Chicago: University of Chicago Press, 1992) 224

${ }^{33}$ Halbwachs 224-225

${ }^{34}$ Halbwachs 222
} 
emphasized the fact that memory is not individual phenomenon, but a largely collective one which is formed by the existing social narratives that drive social, political, and individual behaviour.

In the interest of preserving definitional consistency and conceptual clarity with the existing scholarship, this thesis will adopt the "bottom-up" approach and utilize a definition of collective memory rooted in Halbwachs' work. Collective memory can be understood as a shared pool of memories, knowledge, and information of a social group that is significantly associated with a group's identity. This collection of memories is a socially constructed phenomenon which is the product of the interaction of "common memory" - the recollections of what is experienced in common - and "historical memory" of the instrumentalized memory policies of those in power. It should also be noted that the socially constructed 'historical memory' and the present nature of 'common memory' are both deeply intertwined with cultural discourse but in very different ways. Historical memory is the image of history which is crafted by the state and imposed on the public while common memory simply defines the perception of current events by the public at large. Taken together, these two fundamental components provide a broad definition of collective memory that accounts for its various facets but defines those characteristics within a set of conceptual boundaries that can support the research work of this thesis.

In the context of this thesis, the nature of the observed phenomenon, the described goals the research question, and the exploratory nature of the study, this thesis will place its conceptual emphasis on the 'historical memory' aspect of collective memory and examine how far-right parties build their own historical memory and utilize it in their struggle for cultural hegemony. Moreover, the incorporation of the 'instrumental presentist' of this aspect of collective memory 
will provide insight into how, when, and why, certain discursive techniques and memory policies are being utilized by these far-right parties to establish their own set of narratives.

In order to facilitate the exploratory nature of this thesis, the substance of historical memory will remain broad and include a wide variety of discursive utterances including direct references, direct and indirect speech, and rhetorical figures. This allows this thesis to account for the relationship between culture, history, and identity while staying firmly based on Halbwachs' original arguments on the inherent connection of historical memory to cultural discourse. In sum, this thesis will seek to utilize this aspect of collective memory as the conceptual basis for understanding how far-right parties have created their own 'historical memory' policies and over time, across countries, and how they have been utilized in their newly institutionalized positions.

The definitional portion of this review has demonstrated that the conceptual issues with collective memory are primarily definitional in nature and, with the development of a clearly delineated set of conceptual boundaries, its conceptual shortcomings can be overcome in a political context. The working definition thus allows for a proper assessment of the viability of applying collective memory to the research question and its prospects a means for studying farright political parties. While the decision to from the perspective of 'historical memory' sets the conceptual stage for this thesis, the question remains as to how collective memory should be applied to the practice of conducting research in political science.

While there is some acknowledgement of the potential value of considering collective memory in political analysis, there is less consensus on the means by which any clearly delineated derivation of the concept would be conceptualized in scholarly research. The general lack of definitional clarity has led to the propagation of a number of approaches all of which 
accept the paradigm of collective memory but, like the definitions themselves, vary in their aims, standards, and methodology. After considering the many frameworks highlighted in this review, they all seem ill-suited to directly address the relationship between collective memory, cultural backlash, and the use of history in far-right discourse. The two most comprehensive conceptual approaches each have a glaring flaw which precludes their application to the research goals of this thesis. Individual level frameworks, which focus on the mnemonic dynamics at the individual level, are simply too 'demand-side' focused for the research goals of this thesis which focuses on the 'supply-side' of party strategy. ${ }^{35}$ Collective frameworks, which focus on how groups conceptualize and apply memory as a society at large, offer promising insights from a cultural perspective but suffer from the same problem due to their emphasis on understanding the groups who remember not the actors who dictate the memory. ${ }^{36}$

Perhaps the most prominent conceptual framework for the study of collective memory are institutional frameworks which seek to understand the structures.${ }^{37}$ Despite their prominence in the study of collective memory and the prospects of study the political aspects of institutionalized conceptions of memory, they are problematic for the subject of this thesis because contemporary far-right parties simply do not have the institutional continuity required for the study of electoral programs. Their narrow focus also precludes the consideration of many of the cultural factors which are intrinsically connected to understanding collective memory and its role in cultural backlash. While some frameworks such as the generational, conflict, and approaches also present some avenues for potential research, they are largely underdeveloped and lack the analytical rigour needed for the study of discourse in their current iterations. With

\footnotetext{
${ }^{35}$ Verovšek 5334

${ }^{36}$ Verovšek 536-537

${ }^{37}$ Verovšek 534-535
} 
all other conceptual avenues exhausted, the only solution to this impasse seems to be the construction of a conceptual framework that is unique to the research goals of this thesis, a task which will be accomplished through a substantive review of relevant literature on both collective memory and far-right party discourse.

\section{The Substantive Case for Collective Memory}

Given the lack of a well-defined conceptual framework for analyzing collective memory, this thesis will construct a unique conceptual framework that is tied directly to the goals of the research question. The first step in this process is to examine the substantive findings of political scientists on the subject of collective memory in order to assess the prospect of integrating it into the conceptual framework of this thesis. While there has been a wide array of criticism levied at the conceptual difficulties of working with collective memory, there is considerable optimism among scholars with regards to its integration into political analysis.

A cursory glance at the relevant literature reveals a sort of preoccupation with the potential insights of collective memory especially among scholars of political science. ${ }^{38}$ As Peter Verovšek has noted "in many cases, memory has real perlocutionary consequences, changing the way that important actors think about and react to situations in the present. This makes the politics of memory into an important new area of research for political science." ${ }^{39}$ In fact, the interest in collective memory has become so prevalent that it has become an increasingly relevant subject among scholars of scholars of international relations, comparative politics, and

\footnotetext{
${ }^{38}$ Claudio Fogu and Wulf Kansteiner. "The Politics of Memory and the Poetics of History" in The Politics of Memory in Postwar Europe eds. Richard Lebow, Wulf Kansteiner, and Claudio Fogu (Durham, NC: Duke University Press: 2006) 284-310

${ }^{39}$ Verovšek 530-531
} 
political theory many of whom have long considered implicit concepts like collective memory to be too difficult to properly integrate into existing methodological frameworks. ${ }^{40}$

The preoccupation with collective memory in such a large body of scholarly research demonstrates the potential significance of the concept in the workings of politics and the framing of political issues through discourse. ${ }^{41}$ Given the deficiencies of the existing body of theoretical frameworks, this research represents an ideal starting point for the construction of a new approach which is specifically tailored to address the relationship between collective memory, cultural backlash, and the contemporary far-right. After considering the research goals of this thesis, there are three substantive aspects of this research which stand out as cornerstones for the constructions of a framework for understanding the use of history in far-right party programs: the conceptualization of collective memory as a form of power, its role in the establishment of political norms, and its role in the framing of political issues especially in the context of nationalism.

The fundamental basis for much of the political research on collective memory is born from the idea that collective memory and, by extension, the control of collective memory by political entities is a form of power. This is derived from Halbwachs' work on collective memory which, as explained above, conceptualizes the historical memory portion of collective memory as a set of 'memory policies' which are created and utilized by those in power to support desirable narratives which support the nation. While the public does experience its own 'common' memory, Halbwachs argues that individual memories of events outside the scope of their lived experience are always influenced by the instrumental presentism of the elite. As Jan Assmann

\footnotetext{
${ }^{40}$ Z. Wang 4-5

${ }^{41}$ Z. Wang 6-7
} 
notes "the contents of cultural memory, the ways in which they are organized, and the length of time they last are for the most part not a matter of internal storage or control but of the external conditions imposed by society and cultural contexts. ${ }^{\prime 42}$

Scholars of collective memory have built on these ideas by arguing that collective memory must be conceptualized as a form of power and a means of control. ${ }^{43}$ As Herbert Hersch has noted "the control of memory is a form of power. Persons in a position to manipulate memory, and with it the valued symbols of a society or group hold political power." ${ }^{44}$ In a political context, it is the ability for political actors to exert influence through the commemoration, glorification, and sometimes elimination of the memories of certain events which make it an object of political power. While there has been relatively little attention paid to collective memory in the field of political science, scholars Andrei Markovits and Simon Reich have argued that collective memory is "a major ingredient of the political arena, the public discourse, and the policy setting in every country. It circumscribes the acceptable. It defines such key ingredients as pride, shame, fear, revenge, and comfort for a large number of a country's citizens." 45 The key to the application of collective memory's power in a political setting is based on its influence on both the development of social, cultural, and political norms as well as the development of the emotional responses to certain issues or events. Since these are generally connected to the state's desire to forge a nation-centred group identity, a thorough understanding of collective memory essential to understanding the appeal of nationalism. ${ }^{46}$

\footnotetext{
42 Jan Assmann. Cultural Memory and Early Civilization: Writing, Remembrance, and Political Imagination (Cambridge: Cambridge University Press, 2011) 5-6

${ }^{43}$ Herbert Hirsch. Genocide and the Politics of Memory: Studying Death to Preserve Life (Chapel Hill: University of North Carolina Press, 1995) 23-24

${ }^{44}$ Hirsch 24-25

${ }^{45}$ Andrei S. Markovits and Simon Reich. The German Predicament (Ithaca, NY: Cornell University Press, 1997) 9

${ }^{46}$ Markovits and Reich 10-11
} 
While this is generally conceptualized from the perspective of the state, the recent surge in the contestation of historical narratives as part of cultural backlash necessitates further examination of the links between collective memory and nationalism. According to scholars like Anthony D. Smith, collective memory is a central component of the far-right appeal because myths, memories, traditions, and symbols of ethnic heritage are the central concepts of the nationalistic appeal. ${ }^{47}$ Memory is, after all, a form of power and as they are changed to fit a desired set of narratives, strategic application of collective memory can be used as a tool to mobilize mass support, provide political legitimacy, and especially during times of conflict. Moreover, it provides positive images of the group itself as they engage in self-justification, selfglorification, and self-praise all of which are connected to the emotional roots of collective memory. $^{48}$

The significance of collective memory in the establishment of social, political, and cultural norms invariably leads to its influence being exerted in political discourse but how exactly does this occur in practice? Many scholars have argued that collective memory plays a significant role in the 'framing' of political positions and, by extension, political discourse. As Wang notes, individuals usually approach instances of political conflict through the development of 'frames' which allow for the gathering, processing, and analysis of information. While many scholars point out the collective memory is not the only factor which influences framing, they provide a key "lens" by which the underlying structure of beliefs, values, and experiences of a specific group all contribute to decision-making during times of political conflict. ${ }^{49}$ Discourse is

\footnotetext{
${ }^{47}$ Anthony D. Smith. Myths and Memories of a Nation (Oxford: Oxford University Press, 1999) 9-10

${ }^{48}$ Daniel Bar-Tal. Intractable Conflicts: Socio-Psychological Foundations and Dynamics (Cambridge: Cambridge University Press, 2013) 148-149

${ }^{49}$ Z. Wang
} 
an extension of the conclusions of these frames is therefore likely to be influenced by the formulations of framing based on collective memory. If, as scholars argue, the underlying collective memory which determines these frames is controlled by those in power, they could have a significant effect on how issues are framed, perceived, and presented within the realm of public discourse. With this in mind, it is essential that the existing frames utilized by the contemporary far-right be understood in order to fully understand how they are used to refer to history and whether they have changed over time. With respect to references to history, there are two strategies which are present in the existing literature, revisionism and reframing, both of which will be described in detail in the sections below.

\section{Revisionism in Far-right Discourse}

The majority of far-right parties in Europe have some sort of association with the fascist regimes of the twentieth century be it directly or indirectly and therefore unsurprising that they engage in historical revisionism. It is for this reason that earlier works on collective memory in far-right party discourse were typically conceptualized within the conceptual bounds of historical revisionism and was primarily concern with the method and means by which far-right parties expressed those views internally and externally. Historical revisionism focuses on the reinterpretation of historical record, and, in the case of the far-right, the negation of certain aspects of history which conflicts with far-right narratives. Revisionist discursive strategy could involve a number of different methods including denial of facts or widely established view on those facts, reinterpretation of motivations of historical actors, or advocating for new interpretations of events by the public at large.

The adoption of this conceptual basis of far-right discourse is most salient in scholarship from the 1990s in what is likely a response to the resurgence of neo-fascist parties at that time. 
Many of these parties openly espoused historical negationist views on Nazi Germany and fascism in general denying war crimes, demanding lost territory be returned, and practicing holocaust denial. ${ }^{50}$ Their tone was often revolutionary and, with respect to history, was focused on breaking the "oppressive" post-war consensus on history established by the Allied victors. ${ }^{51}$ These types of discursive strategies are direct rather than indirect which are more common among contemporary far-right parties. Revisionist strategies point to specific events in history in order to deny or revise the perception of those events. While there may be some attempts to reframe public perception of certain events the strategy is based primarily on directly addressing, revising, and sometimes eliminating certain aspects of history which conflict with the nationalistic leanings of the far-right party. Although scholars have noted the vast majority of far-right parties have shifted away from overtly neo-fascist discourse, it is worth noting that and it provides a useful comparator for this analysis because, if there has been a shift towards reframing strategies.

\section{Reframing Strategies in Far-right Discourse}

Scholars of political discourse have made some progress on the subject of far-right which has been the subject of a wide variety of discourse-based research since over the past decade. The nature of their findings is best described in the work of Ruth Wodak, who, after pioneering the practice of critical discourse analysis, conducted extensive research on the political discourse of far-right political parties in Europe. While Wodak's work focuses primarily on analyzing discursive activity in a broader context, her work also addresses many of the substantive aspects

\footnotetext{
${ }^{50}$ Roger Eatwell. "Holocaust Denial: A Study in Propaganda Technique," in Neo-Fascism in Europe eds. L. Cheles, R. Ferguson and M. Vaughan (London: Longman, 1991) 121-122

${ }^{51}$ Roger Eatwell. "How to Revise History (And Influence People?), Neo-Fascist Style," in The Far Right in Western and Eastern Europe eds. Luciano Cheles, Ronnie Ferguson, and Michalina Vaughan (London: Longman, 1995) 308309
} 
of far-right discourse with a focus on strategy, and discursive techniques both in writing and speech. In observing the significant shifts in discursive norms which took place during the late 1990s and early 2000s, a process which she calls the 'Haiderization,' Wodak pointed out that this change was based on a concerted effort by far-right parties to move away overtly neo-fascist discourse and towards a 'populist nationalist' ideological basis in order to broaden their appeal. ${ }^{52}$ She points out that this new discursive focus is situated squarely on the protection of homogenous national identities, cultural heritage, and the preservation of a 'mythical' homeland..$^{53}$

Growing cultural backlash has led to increases in discourse connected to collective memory as appeals to history, culture, and tradition are met with emotional responses from the public. However, in order to avoid the negative connotations associated with revisionism, many far-right parties have chosen to either reframe nationalistic conceptions of history through positive frames or choose to focus on certain aspects or instances of history while ignoring others that would be deemed problematic. Wodak argues that propagation of this type of discourse has caused a fundamental shift in discursive norms as the contemporary far-right parties utilize this type of discourse to emphasize a range of issues. Wodak points out that the consequence of this "opening" of political discourse has been a marked increase in racist and discriminatory discourse albeit varying considerably by medium. With respect to party program, which are the subject of this thesis she argues that far-right parties engage in 'coded' forms of discrimination especially in their electoral programs. ${ }^{54}$

\footnotetext{
52 Wodak 2013, 24

${ }^{53}$ Wodak 2013, 25-26

${ }^{54}$ Wodak 2013, 23
} 
Wodak's work offers a number of useful insights into the current state of far-right discourse there are some gaps in her work that could be addressed by the research work of this thesis. Wodak places little emphasis on the role of history itself instead choosing to focus largely on the instrumentalization of culture and identity for the purpose of legitimizing exclusionism. From a substantive perspective, Wodak tends to focus on the broader discursive strategies, and techniques of far-right parties with little attention paid to the substance of their writings. For example, she states that the far-right engages in coded discriminatory discourse in their electoral programs but fails to elaborate on that point as she delves into an investigation of discursive techniques. ${ }^{55}$ It is clear that Wodak's work has made significant strides in the study of far-right discourse but her focus is clearly trained on racism as she conceptualizes cultural, and historically based discourse only as coded attempts to espouse those views. ${ }^{56}$ Despite the growing prevalence of this type of discourse among far-right parties, its links to collective memory and the profound connections ideological basis of the far-right there is a distinct lack of research on whether it connects to other aspects of contemporary society such as cultural backlash. While Inglehart and Norris' work has opened up new avenues for research on the cultural and historical aspects of far-right discourses, the current scholarship is lacking, and it is within these gaps that this thesis will be situated.

\section{Bridging the Conceptual Gap}

This chapter has consisted of a literature review of a wide variety of scholarship the vast majority of which is interdisciplinary in nature and lies outside the bounds of political science. This was necessitated by the which resulted sheer variety of sources and the underdeveloped

\footnotetext{
${ }^{55}$ Wodak 2013, 26-27

${ }^{56}$ Wodak 2013, 28
} 
state of collective memory in political science which may leave even the most astute reader of this thesis with more questions than answers. So how does one put all this together? The basis for the construction of the conceptual framework for this thesis begins within the body of sociological theories on collective memory proposed by Halbwachs. It is clear that within Halbwachs' original model of collective memory, which conceptualizes the control of historical memory as exclusive to the state, a conflict is emerging due to the advent of cultural backlash. However, this is an issue in countries with problematic pasts such as Germany and Austria where revisionism has such negative connotations that strategic revisionism is an ineffective means of controlling collective memory. According to scholars of discourse analysis, this has inspired many far-right parties to adopt an alternative "reframing" strategy which seeks to control narratives of collective memory by reframing or reinterpreting other aspects of their nation's past instead of simple revisionism.

The presence of these two types of discursive strategies in the existing literature necessitates the creation of a typology which accounts for the major strategies and allows them to be sufficiently linked to the research question and refined to the address the hypothesis. It is clear from the preceding sections of this chapter that the two most prominent strategies for utilizing collective memory in far-right discourse are revisionism and reframing with some evidence that reframing has become the preferred strategy for the contemporary far-right. Since the research question of this thesis seeks to understand how far-right parties reconcile their positive association to history in countries with problematic pasts, the presence of these strategies and the typology they create provide a firm conceptual framework for the research work of this thesis which will evaluate their usage in the context of contemporary cultural backlash. 
After considering the typology created in this chapter, it is clear that a set of categories based on the revisionist/reframing dichotomy is necessary for the discourse analysis. These categories will be divided two basic sets of questions which have been established that address the research question at different levels of analysis. They will act as a loose set of 'categories' which will be used to direct the focus of the analysis towards the goals of the research question. Since this thesis is exploratory in nature and there is a distinct lack of any uniform methodological approach, these questions are utilized to establish a practicable body of data connected to the goals of the research question. However, the primary focus of the qualitative analysis will be the revisionist/reframing divide established in this chapter with specific attention paid to the use of direct and indirect references to history. They will not be quantified but used to build a set of central themes related to the research question that will guide the discussion of the findings and allow for the comparison of the results across texts, between countries, and over time.

The first set of categories seeks to address the research question directly by asking a set of categories are based on the following questions: How do the programs refer to history? Do the programs reference history directly or indirectly? What is the frequency of these references? The second set of categories seeks to engage with material at a deeper level by asking questions which delve into the meaning of the references to history within the broader context of the program. The second set of categories is based on the following questions: Are the references positive or negative in nature? Are they confrontational or non-confrontational? Are the references used instrumentally? In practice, these categories will be tested through qualitative analysis during which they will actively engage with the contextual basis of collective memory to produce a body of data that will be discussed as part of the analysis. 


\section{III: Methodology}

"The politics of collective memory - impossible to quantify, hard to measure, with the methods of survey research, yet still very real - is a major ingredient of the political area, the public discourse, and the policy setting of every country."

- Andrei S. Markovits and Simon Reich (1997)

With the conceptual basis of collective memory firmly established, the following chapter describes the development of the methodological framework which will be used to produce, measure, and analyze data to investigate the programmatic use of collective memory by far-right parties. In order to address the methodological issues commonly associated with collective memory, the development of this framework will consist of a systematic literature review which examines research methods used in the study of both collective memory and far-right parties respectively. The primary goal of this review is to determine the most effective research method for studying collective memory and assess the prospect of integrating it into existing scholarship on far-right parties to inform the research methods of this thesis.

In practice, this review focuses solely on the methodological aspects of the existing literature with a focus on the challenges of conducting research in both fields, current trends in methodological approaches, and identifying gaps in the scholarship that can addressed by this thesis. Its primary goal is to determine the most effective research method for studying collective memory and assess the prospects of integrating it into existing scholarship on far-right parties. The key findings of this review will then be used to situate it within the broader context of the literature, construct a feasible study, and inform its choice of research methods. The body of this chapter will be divided into two distinct parts: the first will consist of the review and an analysis of its findings while the second will describe the methods that will be used to conduct the study. 


\section{The Trials and Tribulations of Memory Studies}

Since the earliest days of memory studies there was concern among some scholars that the broad scope of collective memory and its lack of objectivity in its methodological approach would result in a lack of analytical rigour in its research. ${ }^{57}$ Peter Burke argued that the proliferation of historical memory would be hampered by its interpretive nature such that "neither memories nor histories seem objective any longer. In both cases we are learning to take account of conscious or unconscious selection, interpretation, and distortion. In both cases this selection, interpretation and distortion is socially conditioned. ${ }^{" 58}$ Moreover, historians like Gabrielle Spiegel have long argued that the dominance of collective memory threatened analytical methods of analytical historiography because it failed to "keep the past the past, to draw the line, as it were, that is constitutive of the modern enterprise of historiography." 59 While the majority of these criticisms came with a modicum of appreciation for the potential of collective memory, scholars like Martin Duberman advocated for abandonment of the concept completely "the past will always remain 'uncompleted': we will never grasp its meaning as a whole, never understand its influence over our lives to the extent we like, nor be able to free ourselves from its influence." ${ }^{60}$

Despite the criticism, one might expect the conceptual potential for collective memory to influence politics to have produced a correlating body of scholarship on the subject but the methodological issues described above have left it undeveloped within the field of political

\footnotetext{
57 Imre Lakatos and Alan Musgrave. Criticism and the Growth of Knowledge (Cambridge: Cambridge University Press, 1970)

${ }^{58}$ Quoted in Thomas Butler. Memory: History, Culture, and the Mind (New York: B. Blackwell, 1989)

${ }^{59}$ Gabrielle M. Spiegel. Stories of Peoplehood: The Politics and Morals of Political Membership (New York: Cambridge University Press, 2003)

60 Martin Duberman. The Uncompleted Past (New York: Random House 1969) xii
} 
science.$^{61}$ Langenbacher and Eigler postulated that political scientists were long averse to the study of collective memory because its qualitative nature conflicts with the trend towards rationalist methodological paradigms. ${ }^{62}$ As established approaches to the study of collective memory became increasingly compartmentalized, general trends in research methodology drew political scientists away from collective memory leaving it neglected until recently. ${ }^{63}$ These issues are tied to the individualistic nature of data collection methods in political science, which are difficult to apply to the group context and the study of identity both essential components of collective memory The use of interaction-based research such as interviews, for example, is largely ineffective for studying collective memory due to their unreliability in the face of sensitive historical issues that conflict with existing narratives. ${ }^{64}$

While the ideational elements of collective memory cannot be easily subjected to objective measurement, its cultural significance is often reflected in social texts providing a reliable source of workable data which would otherwise be difficult to attain through traditional methods. The textual basis of content analysis allows for the use of a wide range of materials all of which can be considered to be connected to the cultural discourse at the conceptual basis of collective memory. Moreover, the use of social texts also aids in the study of collective memory due to their tendency to be centred around significant historical events involving glory or trauma which are crucial for understanding a country's memory culture. ${ }^{65}$

Within the framework of content analysis, critical discourse analysis has become an increasingly popular method studying collective memory due its focus on interpreting the

\footnotetext{
${ }^{61}$ Jan Müller. Memory and Power in Postwar Europe (New York: Cambridge University Press, 2002) 1-2

${ }^{62}$ Langenbacher and Eigler 1-2

${ }^{63}$ Wüstenberg and Art 71-72

${ }^{64} \mathrm{Z}$. Wang $84-85$

${ }^{65}$ Wertsch and Roediger 320-321
} 
narratives which drive identity and perception. As Wang notes, "national narratives provide the architecture for the perceptions and actions of national policy makers, and memory and trauma are functions of the narratives that are anchored by experience and sewn into culture."66 Narratives and, by extension, social texts are intrinsically connected to the processes of collective remembering because historical representation itself is a process of social construction which is embedded into the underlying current of cultural discourse. ${ }^{67}$ The utility of this discourse analysis thus lies in its ability to understand collective memory through the 'means' of narratives and 'medium' of social texts both of which are essential to its conceptual function in society as a whole. The conceptual links between collective memory and historical narrative has also led to discourse analysis has becoming a preferred method of analysis for scholars of extremist politics many of whom are sceptical of the applicability of quantitative methods in a world of political disruption and rapidly shifting cultural norms. ${ }^{68}$ The methodological flexibility of discourse analysis and its connections to culture has facilitated its integration with history, theory, and communications to produce a number of conceptual frameworks all of which work from the underlying basis of discourse theory. ${ }^{69}$

The 'discourse-historical approach' (DHA) is of particular interest to this thesis as its problem-oriented nature allows for a degree of conceptual flexibility that accounts for the challenges of working with an implicit concept like collective memory. Moreover, DHA's focus on historical subjects, historical anchoring, and changes in historical discourse makes it ideal for

\footnotetext{
${ }^{66}$ Z. Wang 79

${ }^{67}$ Norman Fairclough. "Critical Discourse Analysis as a Method of Social Scientific Research," in Methods of Critical Discourse Analysis ed. Ruth Wodak and Michael Mayer (London: Sage Publications, 2001) 123-124

${ }^{68}$ Andrea Mammone. "The Eternal Return? Faux Populism and Contemporarization of Neo-Fascism Across Britain, Italy and France," Journal of Contemporary European Studies 17, No.2 (2009) 171-172

${ }^{69}$ Nico Carpentier and Benjamin De Cleen. "Bringing Discourse Theory into Media Studies: The Applicability of Discourse Theoretical Analysis (DTA) for the Study of Media Practices and Discourses," Journal of Language and Politics 6, No. 2 (2007) 286-287
} 
the study of political discourse, particularly in the case of far-right parties many of whom engage in forms historical revisionism. While the nature of DHA is based primarily on interpreting discourse, the integration of collective memory into these types of studies could facilitate broader socio-political analyses which extends their findings beyond the bonds of discursive theory and into the frameworks of political science.

\section{Memory in Far-right Party Scholarship}

It is clear from the initial findings of this review that critical discourse analysis of collective memory represents the most promising method for analyzing the programmatic use of history and collective memory by far-right parties. However, since this thesis is primarily a work of political science, the question remains as to how the integration of this type of research would fit in to the existing scholarship on far-right parties. The far-right has long been an object of fascination among scholars of political science many of whom have yearned to understand how they could function in contemporary liberal democracies. In fact, the study of far-right parties has produced an extensive body scholarly literature which eclipses all other types of political parties combined. ${ }^{70}$ As Tim Bale notes, there is an "insatiable demand" for studies on far-right politics which has only grown in the wake of its resurgence across Europe and North America. ${ }^{71}$ However, the immense size and scope of the literature has not precluded the propagation of key research gaps, methodological disjunctions, and underdeveloped concepts which could be addressed by this thesis. Given the party-based focus of this research, it is essential that this body

\footnotetext{
${ }^{70}$ Cas Mudde. "The Study of Populist Radical Right Parties: Towards a Fourth Wave" C-REX Working Paper Series, No. 1 (2016) 2-3

71 Tim Bale "Supplying the Insatiable Demand: Europe's Populist Radical Right," Government and Opposition 47, Vol. 2 (2012) 256-257
} 
of literature be reviewed and contrasted with in order to assess the body of methodological approaches and situate this thesis within the broader context of the scholarship.

Generally, the current wave of scholarship on the far-right has been characterized by a shift towards to the supply-side of far-right parties, integrating socio-economic factors, and understanding the effects of modern phenomena such as globalization and cultural backlash. There have been concerted efforts to expand the scope of far-right party scholarship to Eastern and Central Europe but the vast majority of studies on far-right parties focus on what Mudde called the 'usual subjects' in terms of countries and parties studied as well as issues addressed. The vast majority of these studies are centred on Germany, France, and the United Kingdom with a focus on smaller countries, emerging far-right parties or cross-national comparison. ${ }^{72}$ In terms of subject-matter, many scholars have chosen to focus their supply-side studies on the framing of specific salient issues such as Euroscepticism, immigration, and racism, with only modest consideration given to other issues in recent years and little consideration of collective memory. Moreover, there is a lack of studies which truly integrate any of these issues into a broader theoretical framework for understanding the supply-side dynamics of far-right parties. ${ }^{73}$

There are a number of significant gaps within these general research gaps which this thesis could address from a methodological perspective. The long-standing focus on quantitative analysis has led to certain degree of stagnation with regards to the production of new theory or variable data. ${ }^{74}$ This is punctuated by the fact that the majority of data used for quantitative studies of far-right parties comes from institutional sources like Eurobarometer, World Values Survey and the European Social Survey. As Cas Mudde notes "New scholarship should go

\footnotetext{
${ }^{72}$ Mudde 2016, 5-6

${ }^{73}$ Mudde 2016, 4

${ }^{74}$ Mudde 2016, 8-9
} 
beyond the comfort zone of detached quantitative electoral studies of the same problematic sources (e.g. Eurobarometer, World Values Survey) and descriptive qualitative historical studies of the same parties (e.g. British National Party, Front National)." ${ }^{.75}$ This has prompted some researchers to diversify their existing data sets through integration of complex variables such as perception and identity. ${ }^{76}$ The trend towards quantitative studies has led to a general lack of quality qualitative studies which utilize alternative research methods such as interviews or participant observation. With respect to contemporary politics, there is also a lack of research which considers the effects modern cultural backlash or the integration of far-right parties into the institutionalized party system.

There has been a wealth of scholarship on the subject of far-right politics over the past several decades but the vast majority of party-based literature involving collective memory comes from the late 1990s during 'second wave' of far-right party scholarship which focused primarily on understanding how far-right populist parties could be successful in functioning democracies through the use electoral studies based on the "normal pathology" thesis. ${ }^{77}$ In terms of their substantive contributions to memory studies, these studies were conducted on the 'usual subjects' the vast majority of which were small far-right in Germany and the United Kingdom. Moreover, they were mostly internally oriented, focusing on pamphlets, newspapers, and internal party discourse instead of officially sanctioned external party communications directed at the general public. ${ }^{78}$ At the time, this tendency was necessitated by what Roger Eatwell described as

\footnotetext{
${ }^{75}$ Mudde 2016, 10-11

${ }^{76}$ L. Bos, W. van der Brug, and C.H. de Vreese. "An Experimental Test of the Impact of the Style and Rhetoric on the Perception of Right-Wing Populist and Mainstream Party Leaders," Acta Politica 48, No. 2 (2013) 192-193

77 Mudde 2016, 3-4

${ }^{78}$ Mudde 2016, 9-10
} 
the disjunction between the "exoteric and esoteric" faces of far-right parties which asserted that their external are not usually indicative of the party's core values and beliefs. ${ }^{79}$

The difficulty in reconciling the disjunctions described by Eatwell combined with the 'second-wave' scholarship and a lack of unified methodological approaches to the study of collective memory in the form of historical revisionism which was relatively salient at the time. However, the vast majority of studies on far-right parties which utilize historical revisionism treated it not as a significant element of their discourse, but a minor contributory component in favour of more conceptually robust factors such as nationalism, racism, and authoritarianism. This was particularly prevalent in the study of party ideology which often utilized historical revisionism as a criterion for determining ideological differences within the far-right party system. For example, Cas Mudde routinely includes historical revisionism as a key contributory factor in his content analysis of externally and internally oriented party documents. ${ }^{80}$ Similar studies by Hans-George Betz, Piero Ignazi, and Herbert Kitschelt have also mentioned historical revisionism as a categorical marker for their studies of far-right party ideology. ${ }^{81}$

It is clear that collective memory, or in this case historical revisionism, was acknowledged and considered in broader studies of far-right parties in the past but there is a distinct lack of dedicated research which directly addresses its role in the party dynamics, framing of issues, and political discourse of the far-right. Moreover, collective memory has been studied primarily within in the conceptually narrow bounds of historical revisionism, a concept

\footnotetext{
${ }^{79}$ Eatwell 1995, 310

${ }^{80}$ Cas Mudde. The Ideology of the Extreme Right. (Manchester: Manchester University Press, 2002) 20-21

${ }^{81}$ Piero Ignazi "The Silent Counter-revolution: Hypotheses on the Emergence of Extreme Right-wing \{arties in Europe," European Journal of Political Research 22, No. 1-2, (1992) 3-34, Hans-George Betz "The Two Faces of Radical Right-wing Populism in Western Europe," Review of Politics 55, No.4 (1993) 663-85, Herbert Kitschelt The Radical Right in Western Europe: A Comparative Analysis (Ann Arbor: The University of Michigan Press 1995)
} 
which has become largely obsolete in the wake of the move away from overtly neo-fascist discourse among contemporary far-right parties. ${ }^{82}$ While there has been some progress made in understanding the nature of collective memory in its revisionism form, the circumstances surrounding the resurgence of the far-right combined with the significant shifts in cultural discourse warrant the development of an approach which accounts for the complexities of ongoing cultural conflicts, identity politics, and the changing role of history in the increasingly globalized modern world. By adopting a broader approach based in a more comprehensive conceptual basis such as collective memory, this thesis will seek to produce a methodological framework which better suited for studying contemporary far-right parties.

\section{Collective Memory in Critical Discourse Analysis}

Perhaps the most notable development in the study of far-right parties is the development of critical discourse analysis in the early 2000s. While collective memory was largely neglected or conceptually narrowed during the 'second wave' of scholarship, the advent of conceptual flexibility and interdisciplinary nature of this new qualitative method allowed for the study of cultural and historical narratives through discursive frameworks. From 2004 onwards, interest in discourse analysis grew steadily and scholars began to apply these techniques to analyze the role of identity and collective memory in response to contemporary phenomena such as European Integration. ${ }^{83}$

The veritable explosion of interest in critical discourse analysis of political parties in the mid 2000s is largely attributed to a significant shift in discursive norms caused by far-right

\footnotetext{
82 Wodak 2013, 25-26

${ }^{83}$ Reisigl, M. "The Dynamics of Right-wing Populist Argumentation in Austria" In F. H. van Eeemeren, J. A. Blair, C. A. Willard and B. Garssen (eds.) Proceedings of the sixth conference of the international society for the study of argumentation (2007) 1127-1134.
} 
parties, a phenomenon which Ruth Wodak dubbed the "Haiderization" of Europe ${ }^{84}$ In response to Wodak's work, the subject of far-right populism and fascist discourses has drawn considerable attention from scholars of discourse analysis who have utilized critical discourse analysis to examine the conceptualization, instrumentalization, and communication of historical narratives which exploit the mechanisms at the heart of collective memory. Over time, DHA-based discourse analysis become the preferred method of analysis due to the far-right's consistent utilization of historical revisionism and appeals to an idealized past.

The conceptual flexibility of DHA-based discourse analysis allowed for the adoption of a wide range of techniques including the most notable of which included multimodal analysis of fascist discourses textual form and comparative analysis of far-right rhetoric through the analysis of speech. ${ }^{85}$ Moreover, these works on fascist discourses have been conducted in the form of cross-national analyses of far-right groups covering both Europe and the United States. ${ }^{86}$ There has also been a significant number of studies which focused on the utilization of historical narrative as means to frame racist discourse ${ }^{87}$ Some notable examples of this include Copsey and Richardson's analysis of the historico-cultural narratives as a key factor in British fascist discourse, Wodak and Forchtner's study on the exploitation of Ottoman-based anti-Turkish historical narratives, and Krzyżanowski's work on the shifting of Austrian far-right historical narratives towards a Islamophobia. ${ }^{88}$ Over the course of these studies, a wide range of materials

\footnotetext{
${ }^{84}$ Wodak 2013, 24-25

${ }^{85}$ Ruth Wodak and J.E Richardson (eds.) Analysing Fascist Discourse: European Fascism in Talk and Text (London: Routledge, 2013) 5-6

${ }^{86}$ Ruth Wodak. The Politics of Fear: What Right-wing Discourses Mean. (London: Sage, 2015) 5-6

${ }^{87}$ Reisigl 2007, 1127-1128

${ }^{88}$ Copsey, N. and Richardson, J. E. (eds.) Cultures of post-war British fascism. (New York: Routledge, 2015), Wodak 2014, Michał Krzyżanowski. "Continuities and Shifts in Recent Discourses and Patterns of Communication of the Freedom Party of Austria (FPÖ)" in Right-Wing Populism in Europe: Politics and Discourse eds. Ruth Wodak, Majid Khosravinik, and Brigitte Mral (London: Bloomsbury Academic, 2013) 136
} 
were used but there is a strong focus on forms of visual communications such as political posters, leaflets, comics, and television. ${ }^{89}$ Although other textual materials such as books, speeches, and rhetoric were used in some DHA-based studies of collective memory, it should be noted that they were not the primary focus of the discipline or the methodology and are therefore slightly underdeveloped as a unit in the existing body of research.

Despite the size and scope of the discursive literature on far-right parties, there are a number of notable gaps which can be used to orient the research direction of this thesis. First, the majority of DHA-based studies on far-right parties have largely analyzed the collective memory in terms of racist and xenophobic discourse with analytical frameworks of discourse analysis are based primarily on assessing those factors. Second, there is a lack of discourse analyses covering recent political developments in Western Europe during which many far-right parties ascended to positions of power in national parliaments. Apart from recent studies on AfD, UKIP, and FPÖ, the vast majority of scholarship was produced between 2010 to 2016 and thus does not cover the entrance of many far-right parties into the frameworks of the national party system. Moreover, these studies usually explore discursive frameworks related to specific issues such as immigration, citizenship, and racism or have conceptualized the framing of generalized historical narratives as a product of the "civilizational clash" narrative perpetuated by Islamophobic discourse. ${ }^{90}$ Third, most contemporary discourse analyses have focused various forms of media (newspapers, billboards, pamphlets, etc.) and, despite a general acknowledgement that party

\footnotetext{
${ }^{89}$ Martin Riesigl. "The Discourse-Historical Approach," The Routledge Handbook of Critical Discourse Studies eds. John Flowerdew and John E. Richardson (London: Routledge, 2017) 52

${ }^{90}$ Ayhan Kaya and Ayşe Tecman. "Europe Versus Islam? Right-wing Populist Discourse and the Construction of a Civilizational Identity," The Review of Faith and International Affairs 17, No. 1 (2019) 50-51
} 
programs hide subtle forms of discursive intrigue, there is a lack of DHA-based studies which actively utilize the party program as a unit of analysis. ${ }^{91}$

It is interesting to note that the lack of party program-based discourse analysis comes at a time when many far-right parties are attempting to modernize their external image and communications. It is clear from observations and ongoing political developments that far-right parties still espouse views which are contestations to existing narratives of collective memory, be it among its members, leaders, or in an official capacity. With racist and revisionist discourse absorbed by extremist groups, or relegated to localized forms of media, the unprecedented ascension of many far-right parties into the institutional framework of the party system presents an interesting opportunity to analyze how far-right parties have adapted their external framing of historical narratives This process has seldom been studied due to a 'perfect storm' of conceptual difficulties with collective memory, trends towards quantitative research in political science, and the communicative shift in extremist discourse into the cultural rather than the political domain. Given the growing salience of memory contestation in contemporary political discourse, it is clear that the causes, mechanisms, and consequences of their instrumentalization of historical narratives present opportunities for further research.

\section{Bridging the Methodological Gap}

This methodological review has demonstrated that despite the size and scope of the relevant literature, there are a number of significant gaps in the existing scholarship on far-right parties which provide opportunities for the integration of discourse analysis-based research collective memory. Generally, there has been a significant trend towards quantitative studies of

\footnotetext{
${ }^{91}$ Wodak 2013, 25-26
} 
the supply side aspect of far-right parties while quality qualitative studies have been lacking over the past decade. Moreover, recent studies on far-right parties have trended towards studying the consequences of their integration into the party system rather than the causes of their success.

There has also been a tendency for literature on far-right parties to gravitate towards a series of issues which Mudde calls the 'usual subjects'. Immigration, ethnic minorities, and Euroscepticism are overrepresented in the literature despite some movement towards comparative analysis of other issues. Unsurprisingly, these issues are also routinely measured in major datasets such as Eurobarometer, European Social Survey, and the World Values Survey making them easily accessible for 'desirable' quantitative studies. The overuse of this data combined with the trend towards quantitative studies has led stagnated due to a lack of new theory or datasets which must be developed through qualitative analysis. ${ }^{92}$

In examining the role of collective memory in the scholarship of far-right parties, this review determined that despite the far-right's well-documented association with positive and penchant for historical revisionism, there is an absence of comparative quantitative and qualitative studies directly related to the subject. Moreover, collective memory has often been conceptually narrowed when studied in the context of far-right parties which precludes any consideration of the cultural factors which are considered to be essential to understanding its connection to contemporary struggles with identity. While many scholars of have acknowledged that collective memory 'matters' in the study of political parties, it was mainly used as a minor contributory factor to larger comparative studies of far-right parties.

\footnotetext{
92 Mudde 2016, 11-12
} 
Constrained by the conceptual and methodological barriers which plague collective memory, there has been little effort made to study the use of collective memory within the farright party system across countries and over time despite their tendency to be the facilitators of conflicting historical narratives. The field of discourse analysis has flourished producing a plethora of research on the discursive techniques of far-right parties across Europe. The flexibility of discursive frameworks allowed for the analysis of various types of media which comparatively examined trends in issues such as racism, populism, and neo-fascist discourse. However, many of these analyses were focused primarily on these specific issues within communicative mediums such as television, posters, and billboards. There was a distinct lack of engagement with 'official' documents such as party programs despite their acknowledged role as "subtle" communicators of appeals to collective memory. Given the evolution of many far-right parties from outsiders to members the institutionalized party system, discourse analysis which examines the utilization of historical narratives in party programs could provide valuable insight into how these parties appeal to the public and how those communications have change over time.

Given the lack of qualitative studies in the field of far-right politics, the pressing need for diversification of existing datasets, and the lack of attention paid to party programs, a DHAbased analysis of party documents relevant to the external communication of collective memory could add a historico-mnemonic dimension to the study of far-right parties as they ascend to institutionalized positions. The structure of this proposed method of study must reflect the following criteria to address the stated goals of the research question: First, it must be interpretive in nature with the ability to account for the fluid nature of identity, cultural discourse, and the political circumstances of the chosen states. Second, it must be able to 
operationalize the concept of collective memory within a workable interpretive framework. Third, it should aspire to utilize a unit of analysis which is available at regular fixed points to provide data points which account for the 'present' cultural and political circumstances related to collective memory. Moreover, these data points must be over a sufficient period of time so that trends in the utilization of collective memory can be mapped, identified and reconciled with changes in historical memory.

With respect to the existing body scholarship on far-right parties, this study seeks to address its failings through the acknowledgement of its limitations, diversification of existing theoretical frameworks, and the creation of new data through consideration of a previously unexplored concept. Working from the supply-side of party dynamics, this study will seek to address a wide variety of issues which have been identified within the third wave of scholarship on far-right parties. First, it will seek to diversify the existing set of theoretical frameworks by exploring the previously underdeveloped concept of collective memory and adapting the insights of its conceptual frameworks to construct new theory. Second, it will address the need for new data for quantitative studies through the use of qualitative content analysis to explore an underdeveloped aspect of far-right party support. This will build on the work of earlier efforts to diversify data sets with complex variables but push the envelope by exploring an entirely new concept which is applicable across countries and over time. Third, it will avoid the tendency for studies on far-right parties to gravitate towards the 'usual subjects' by theorizing an entirely new issue in the form of collective memory. Fourth, it will explore potential alternatives theories to the underdeveloped status of globalization and cultural backlash in the study of far-right parties both of which have stretched modernization theses at the core of the scholarship to their limits. Finally, it will acknowledge the continuing institutionalization of far-right parties into existing 
political systems by including a wide variety of parties and utilizing a timeline which accounts for shifts in the status of far-right parties.

Consequently, this thesis makes the case for an exploratory comparative case study which examines the use of collective memory by far-right parties across countries and over time using DHA-based analysis. This study would utilize DHA to apply the conceptual frameworks of collective memory to understand the role of historically-based far-right discourse as far-right parties transition into the mainstream party system. In the broader context of both bodies of scholarship, this research can be conceived as a contribution to the bridging of the conceptual gap which exists between the fields of memory studies and political science. While these fields have long been separated by the methodological trends of their respective disciplines, the prevalence of memory and identity in contemporary political discourse combined with a lack of adequate research on the study of far-right parties demands that new avenues of research be explored. Situated firmly at the intersection of political science and memory studies, the goal of this study will explore the possibility of integrating these disciplines through discourse analysis to move beyond the 'usual suspects' to build a foundation for new theory by striving to understand the deeper forces at play in the rise of far-right parties.

\section{Applying the Discourse-Historical Approach}

After working through the exhaustive process of selecting, reviewing, and justifying the use of DHA as the preferred research method for this thesis, it is clear that a more thorough examination of its characterises is required if it is to be properly applied. As previously discussed, before the advent of CDA and DHA, discourse analysis was traditionally seen as a method of linguistic analysis which simply consisted of the analysis of various forms of communication be they written, spoken, or semiotic in nature. DHA expands the conceptual 
boundaries of discourse analysis beyond the confines linguistics by adopting a multidimensional approach which incorporates political, social, and historical factors to discursive insights which contribute to the understanding of social phenomena. The adoption of these factors is based on the assertion that discourses develop around social problems and act as starting points for argumentation which in turn are addressed by multiple perspectives that can be investigated. ${ }^{93}$

Despite the significant differences between DHA and CDA, DHA does not abandon the practical basis of discourse analysis but simply shifts its emphasis away from the sociopsychological and towards the political. As its name implies, DHA places a significant emphasis on the historical dimension, but, much like collective memory, it also incorporates other closely related social factors such as politics, social and culture. ${ }^{94}$ Consequently, the scope of DHA is exceedingly broad with the ability to analyze a wide variety of phenomena through relevant discourse including ideology, identity, and, most notably, collective memory making it ideal for the research focus of this thesis.

An astute reader of this thesis may argue that CDA shares many of the same qualities as DHA and question why it was chosen over certain forms of CDA which have more refined methodological frameworks. Indeed, both methods share a number of similarities in research practice most of which are derived from their common theoretical background. Both methods are application-oriented placing significant emphasis on the practice-related quality of discourse, its context dependence, and the constructive nature of the concept of discourse as a whole. They both reject an orthodox approach to the study of language and chose to expand their conceptual boundaries in order to include macro and micro phenomena, intertextual and interdiscursive

\footnotetext{
${ }^{93}$ Riesigl 2017, 52

${ }^{94}$ Riesigl 2017, 48
} 
relationships, as well as the political, social, and historical factors. No longer bound by the narrow conceptual focus of discourse theory, both methods become 'politically active' allowing them to be applied to broader discussion about social phenomena that are connected to the discourse which they study.$^{95}$ While these shared characteristics all represent desirable qualities for the research focus of this thesis, there are certain aspects of DHA which make it more desirable as a method of analysis.

There are several key differences which set DHA apart from the various existing forms of CDA and make it the preferred method of analysis. First, DHA puts its emphasis on historical subjects and the historical anchoring of discourse much more than other forms of CDA. This, of course, facilitates the analytical process of this thesis due to its focus on references to history within far-right discourse. Second, the practical application of analytical insights such as the process of critique are usually the primary goal. This is particularly relevant to the clash between historically-based rhetoric and memory culture that is defined as cultural backlash. By initiating a process of critique, this thesis can utilize its findings to comment on the social phenomena of history in far-right discourse as a whole. Third, the concept of rhetoric is more comprehensive than CDA. It is considered a form of argumentation and therefore is not considered pejorative as it is often labelled in CDA. This point is crucial for the study of the far-right due to their tendency to use particularly problematic and discriminatory forms of rhetoric. ${ }^{96}$

In practice, the structure of the analytical portion of this thesis will be firmly grounded I the structure proposed by the methodological framework of DHA. This consists of five steps. First, the textual materials related to the discourse of study must be gathered and prepared.

\footnotetext{
${ }_{95}$ Riesigl 2013, 49-50

${ }^{96}$ Riesigl 2017, 47
} 
Second, the context must be established which, in this case, consists of the integration of a macro-level sociopolitical and historical context into the analysis. In this case, collective memory acts as the contextual basis for the analysis and provides the conceptual backdrop for far-right discourse. Third, a broad qualitative analysis that allows for the testing of some basic categories must be conducted in order to produce data related to the given research question. This will be accomplished through the application of a set of analytical categories described below. Fourth, once the texts have been analyzed and their intertextual relationship discussed, a critique based on Wodak and Riesigl's socio-diagnostic model will be formulated on the basis of the findings and contextual backdrop of collective memory which provides the social, historical, and political background knowledge. This critique will be political in nature and focus on the discrepancies between the historically-based discursive practices of the far-right parties and established societal norms involving memory. Finally, the findings of the analysis will be applied to address the research question and draw conclusions. ${ }^{97}$

\section{Units of Analysis}

The most important aspect of any discourse analysis is the unit of analysis is the researcher's choice of textual material which must be accessible, measurable, and applicable to the needs of research question. Consequently, party programs were chosen as the primary unit of analysis for this case study due to a number of distinct advantages with respect to both the conceptual framework and the research question. The conceptualization of collective memory as an 'instrumental presentist' concept which is operationalized to frame issues during political conflict necessitates the analysis of documents which reflect the exercise of that process. Party

\footnotetext{
${ }^{97}$ Riesigl 2017, 48-49
} 
programs are ideal for the purposes of this study due to their strong association with the political conflict of elections and the research potential of analyzing the framing of historical references within their appeal to voters.

With this in mind, party programs provide a number of distinct advantages: First, a party program gives the clearest idea of what a party is advocating at a given point in time and, due to the scope of the election, allows the process of discourse analysis to account for the 'present' aspect of collective memory. ${ }^{98}$ If social texts are a medium for the communication of collective memory, the election can be conceived as the setting in which the powers that wield it conflict. Second, party programs are externally oriented documents aimed at the attraction of voters and thus represent an outlet for the utilization of collective memory in the broadest possible context. Third, the party program provides a degree of legitimacy which surpasses other documents because they are endorsed and published by the party thus can be understood as representing the general will of its members, or at the very least, what they wish to communicate with the electorate. ${ }^{99}$

The choice to study party programs from Germany and Austria requires some additional discussion due to the existence of different types of party programs. In both countries, political parties utilize three types of party programs: Parteiprogramme (party programs), Wahlprogramme (electoral programs), and Aktionsprograme (action programs) each of which serves a specific function within their political system. Party programs are constructed to communicate a party's overarching values, goals, and plans in the medium to long term. Working from the party program, electoral programs are a set of principle goals specifically

\footnotetext{
98 Matthijs Rooduijn and Teun Pauwels. "Measuring Populism: Comparing Two Methods of Content Analysis," West European Politics 34, No. 6 (2011): 1273-1274

${ }^{99}$ Mudde 20-22
} 
designed to garner public support during a given election cycle and are published as a means of communicating the party's values as set of policy goals the party will undertake if they form government. Action programs are a less common variant of party programs which express demands in specific policy areas with varying degrees of scope depending on the party, issue, and election.

Electoral programs were chosen as the primary unit of discourse analysis due to their frequency, accessibility, and compatibility with the goals of the research question. The election is conceptualized as the "setting" for the memory contestation and the electoral platforms Moreover, I focused on federal elections in order to analyze the programmatic use of collective memory in the broadest possible context and to the widest possible demographic across countries and over time. The 'present' nature of collective memory, its intrinsic connection to cultural discourse, and its conceptualization as an instrumental aspect of memory conflict necessitate the use of documents which reflect its use in a political setting in which this conflict can take place. In this respect, the electoral program provides a veritable "snapshot" of a party's desired external communications and at a given point in time allowing for consideration of the ongoing effects of cultural backlash while accounting for shifts in the historical aspects of discursive techniques at specific points in time.

In terms of practicality, it should also be noted that there are a number of factors involved in the decision to use utilize these particular documents including availability, accessibility and language. The nature of the party program means that they are available at regular intervals and produce a measurable scale across countries and over time. Moreover, the official capacity of the party program means they are easily accessible through both official archives and party websites. In terms of language, many contemporary electoral programs are also available in English 
translation, reducing the language burden required for the process of discourse analysis. In terms of analysis itself, the regular frequency of elections provides a set of firmly rooted data points which both reflect and are easily comparable across countries and over time. This makes electoral programs the most applicable document for reliably analyzing and tracking trends in the use of collective memory by far-right parties across countries and over time.

While other types of programs were considered, they both proved insufficient for the proposed critical discourse analysis. Party programs they are usually created to reflect a party's direction over a longer period of time than an electoral program making them less practical for comparative study over time. While party programs may offer a better picture of the internal dynamics of a given party, their wider scope, abstract nature, and internally-oriented focus makes them difficult to apply to the 'present' nature of collective memory in far-right party discourse. Moreover, the production of party programs does not correlate with outlets within which the contestation of memory takes place, a quality that is necessary to meet the goals of the research question. As for action programs, they were excluded for much of the same reasons, namely their sporadic nature, diminishing usage, and limited scope in a contemporary political context.

\section{Timeline}

The timeline for this study will run from 2002 to 2017, a time period which encompasses five federal elections in Germany and Austria respectively. This timeline was chosen to reflect what many scholars believe is a profound shift in the workings of far-right political parties over the past two decades. Scholars of far-right parties have often categorized periods of far-right activity in "waves" each of which reflects the political, cultural, and ideological character of farright extremism of a given time. While we are still, technically speaking, in the third wave of farright extremism which began in 1980 , there has been considerable debate among scholars as to 
whether the recent resurgence of far-right politics can be categorized as a fourth wave since its characteristics differ greatly from the far-right parties of the past. ${ }^{100}$ This also coincides with the emergence of Inglehart and Norris' cultural backlash, which is considered to be a largely contemporary phenomenon.

While the categorization of far-right movements is outside the scope of this thesis it is abundantly clear that the significant cultural, and technological developments of modern society have had a significant effect on far-right politics especially with respect to political discourse. This is largely confirmed by scholars of discourse studies such as Wodak and Reisigl who have consistently demonstrated that there have been significant shifts in far-right discourse since the late $1990 \mathrm{~s} .{ }^{101}$ Therefore, this timeline is placed after the initial shift, this is done to examine the effects of this change in discursive norms in conjunction with the modern societal and cultural developments that have played a part in the resurgence of far-right parties.

It should also be noted that there were a number of practical considerations taken in the decision to adopt this timeline. The decision to situate the timeline at the turn of the millennium was based primarily on the accessibility, availability, and of quality textual material. Prior to the digitization of party programs, the is exceedingly difficult to access the documents necessary for this analysis especially in the context of a project of this size and scope. As was mentioned in the previous chapter, many far-right parties placed little emphasis on party programs and focused on internally-oriented documents during this period. This has led to a situation in which many farright parties either produced no electoral programs at all or simply reproduced the same basic electoral programs with minor additions. Given the decision to use electoral programs as the

\footnotetext{
100 Mudde 2016, 14-15

${ }^{101}$ Martin Reisigl and Ruth Wodak. Discourse and Discrimination: the Rhetoric of Racism and Anti-Semitism (London: Routledge, 2001) 2-3
} 
primary unit of analysis for this thesis, an analysis of electoral programs would be unlikely to provide any substantive findings and contribute little to the goals of the research question.

\section{Parties}

In choosing the parties for the case study, a pluralistic approach was adopted based on Cas Mudde's 'functional equivalence' paradigm which seeks to account for the increasing heterogeneity of far-right parties by operationalizing their categorization. ${ }^{102}$ In this framework, far-right parties are not categorized by ideology, policy, or political orientation but by their equivalent function within their country's party system. This 'function' can be adjusted to meet the needs of a given research question allowing researchers to account for political, cultural, and ideological differences in party composition across countries and over time. In this case, parties were chosen based on their functional equivalency as producers of counter-memory within the context of their party systems. their ideological extremes within that framework.

With this process in mind, the far-right parties selected for the analysis include Alternative für Deutschland (AfD) and Nationaldemokratische Partei Deutschlands (NPD) in Germany, and Freiheitliche Partei Österreichs (FPÖ) in Austria. Why were these parties chosen? Through careful analysis of the electoral programs of each party, I determined that these three stood out as functionally equivalent sources of collective memory within the existing framework of their country's memory culture. I made this determination by assessing their electoral platforms, and examining far-right party scholarship. I identified several reoccuring criteria in this repsect including direct condemnations of established norms in memory culture, and the framing of issues through appeals to history and collective memory. While the

\footnotetext{
102 Mudde 2016, 16-17
} 
substantive focus on the resurgence of the far-right may seem to preclude the consideration of an unsucessful party like NPD in favour of others like AfD and FPÖ, the inclusion of NPD provides a useful ideological counterweight to the novelty of AfD and allows for a more nuanced assessment of how programmatic references to history have changed over time.

Beyond their functional equivalency, each of these parties meets a number of general criteria that make them well-suited to address the research question. First, they are all considered 'far-right' in both scholarly literature and public discourse although it should be noted that there have been some minor variations in ideological orientation over time. Second, they have all contested federal elections on a regular basis allowing for adequate comparative analysis in the units specified above. Finally, these parties have all utilized programmatic references to history in an official capacity within their constituent countries allowing for the analysis of the institutionalization of these views. Within the context of each country, two other key criteria were considered in the selection of parties for the analysis, continuity and ideology. Taken together, these criteria provide an additional supplement to the body of data which will aid in the assessment of the research question.

In order to facilitate the continuity-based aspect of the analysis, two parties were chosen from Germany; one which was firmly established within the far-right party system (NPD) and another that emerged during the recent resurgence of the far-right (AfD). The emergence of new far-right parties such as AfD represent 'challengers' to the existing status quo and their electoral provides an interesting contrast with less successful parties like AfD. Discourse analysis of the differences in these parties' historical discourse could provide insight into both the role of historical references and the differences in their discursive presentation. While the institutional continuity of FPÖ creates an obvious imbalance between Germany and Austria for this aspect of 
the analysis, its presence allows for a more nuanced comparison of the programmatic use of history by far-right parties by accounting for the effects of institutionalization.

In order to account for the ideological differences within the far-right party family, specific parties were also chosen to represent a specific subgroup of the far-right party family within the political context of their country. In Germany, NPD represents the extreme of the farright spectrum representing "old" far-right whose ideology is based on neo-fascist discourse while AfD represents the "new" populist nationalist far-right described by scholars like Wodak. In Austria, the continuity of FPÖ in the party system makes ideological comparison difficult but, within the continuity, there have been significant fluctuations in FPÖ's ideological orientation which warrant just as much attention as the contrasting approaches of parties like NPD and AfD. The inclusion of FPÖ thus provides contrasting insight into the nature of far-right historical discourse in the context of a relatively stable institutionalized far-right party while still providing insight into its ideological relationship to discursive shifts over time. Moreover, the decision to analyze FPÖ's electoral programs for some cross-national ideological comparison which is invaluable due to the historical, cultural, and linguistic similarities between Germany and Austria as well as their contrasting approaches to memory culture.

While the political parties chosen to be part of the analysis have all participated in federal elections within the established timeline, they have not always produced electoral programs which meet the substantive needs of this thesis. There are numerous reasons for this including strategic considerations, structural differences in party communications and the unreliability of textual materials from fringe parties necessitate the omission of certain programs on a case-bycase basis. While there is a sufficient number of programs available to produce a working body 
of data, the chart below details which platforms will be used for each portion of the analysis in the interest of clarity:

\begin{tabular}{|l|l|}
\hline \multicolumn{1}{|l|}{ Austria } & \multicolumn{2}{l|}{ Germany } \\
FPÖ & NPD \\
1) 2002 Wahlprogamm & 1) 2002 Wahlprogamm \\
2) 2009 Wahlprogamm & 2) 2009 Wahlprogamm \\
3) 2013 Wahlprogamm & 3) 2013 Wahlprogamm \\
4) 2017 Wahlprogamm & 4) 2017 Wahlprogamm \\
& AfD 2017 Wahlprogamm \\
\hline
\end{tabular}

Table 1: List of textual materials for content analysis of electoral programs

There are some notable omissions from this body of electoral programs. For the Austrian portion of the analysis the 2006 and 2008 electoral programs are excluded due to a number of factors that are unique to political circumstances in Austria. In 2006, a snap election led FPÖ to produce a very limited electoral program that was largely policy focused and made little reference to direct or indirect references to history. The 2008 election produced a similar electoral program, but it was supplemented with a variety of other materials included several booklets, pamphlets, and which described FPÖ’s cultural positions. Since these electoral programs do not contain relevant passages they have been excluded from the analysis and are only mentioned in passing or in reflection on the general direction of trends in discourse as a whole.

For the German portion of the analysis, NPD's 2005 program is excluded because, for that particular election, the party chose to produce little more than a pamphlet-sized Aktionsprogamme which does not have the substance to warrant any in-depth qualitative analysis. AfD's 2013 Wahlprogramme is also excluded due a lack of relevant passages 
pertaining to history, culture, and tradition. The relatively short period between the founding of the party and the 2013 federal election meant that there was limited time to compose a comprehensive electoral program leaving it short, policy heavy, and based primarily on the economic ideas of former AfD leader Bernd Lucke which are of little relevance to this analysis. However, once the party was firmly in control of challenger Frauke Petry, they added a significant cultural dimension to their party program which was then synthesized into an electoral program for the 2017 federal election.

There are some minor far-right parties which were politically active during the chosen timeline but were excluded from this analysis due to practical considerations including lack of electoral participation, accessibility, and the substantive quliaty of their party programs. ${ }^{103}$ The most notable of these exclusions are Deutsche Volksunion (DVU) and Die Republikaner (REP) both of which have been considered significant in the existing scholarship. ${ }^{104}$ The issue with DVU and REP was the quality of their party programs which were often short, pedantic, and left largely unchanged between elections. Over the past two decades, DVU produced one page-long party program which was sparsely edited until their merger with NPD in $2011 .{ }^{105}$ REP did produce several party programs in the 1980s and 1990 but their plunge into political irrelevance in the early 2000s led to a significant drop in the quality of their programs most of which were left largely unchanged over the last two decades. Their 2017 party program, for example, is a near word-for-word reproduction of their 2002 electoral program and even contains outdated references to the repatriation of East German officials. ${ }^{106}$ It is clear that the lack of substantive

\footnotetext{
103 Mudde 2002, 29-30

104 Mudde 2002, 20-21

105 Mudde 2002, 65

${ }^{106}$ Die Republikaner (2017). Wahlprogramm REP 2017 'Sozial, Patriotisch, Ökologisch' (Election campaign manifesto). Berlin.
} 
change in these texts over time would not produce sufficient data for the proposed discourse analysis.

It should be noted that in addition to FPÖ, there was another right-wing populist party in Austria called Bündnis Zukunft Österreich (BZÖ) which was politically active at the federal level from 2005 to 2017. Founded by Jörg Haider in 2005 after his failed attempt to reform FPÖ, BZÖ was conceived as a 'moderate' alternative after years of internal squabbles within FPÖ. Given its association with Haider and his group of defectors, BZÖ may seem like an obvious choice for an analysis of programmatic use of history and collective memory but there are several issues which have led to its exclusion from the analysis.

First and foremost, BZÖ was never definitively categorized as 'far-right' in the same manner as the other subjects of this analysis. While the influence of former FPÖ members did keep the party firmly rooted in national conservatism and uttered the occasional controversial statement, the party was never firmly categorized as far-right in public or academic discourse. Second, the moderate nature of BZÖ led to the vast majority of their electoral programs. In what is likely a reflection of Eatwell's work on the esoteric and exoteric faces of far-right parties, it appears as though BZÖ attempted to present its moderate image and downplay its relationship to Haider's past by avoiding cultural discussions entirely in an official capacity. This precludes BZÖ's inclusion in this analysis due to its substantive focus, research goals, and choice of textual materials. Finally, after Haider's death in 2008, the party reinvented itself as an economically liberal party under the leadership of Joseph Bucher. This ideological represents a definitive break from the party family being studied in this thesis and warrants its exclusion from the analysis. 


\section{IV: Austria}

"In a period of identity destruction and alienation of people from their roots in the interests of global corporations and financiers, attention must be paid to the ideological commitment to the preservation of their own cultural heritage and language."

- FPÖ Electoral Program (2017)

The following chapter consists of a discourse analysis of the electoral programs of Austria's FPÖ. Relevant quotes each electoral program will be described, analyzed, and discussed within the context of their given theme and the chapter will conclude with a brief discussion which synthesizes the findings of the analysis and engages with the material at a deeper level and consider its relationship to the research question. In accordance with the MSSD approach proposed in the introduction to this thesis, Austria will examined but used primarily as a comparative model to study the emergence of far-right parties in Germany and, given the similarities between both countries, both sections will be structured in a manner which gives equal consideration given to both the established typology and the underlying themes which define the substance of the discourses.

While the primary categories for the analysis is based on the revisionist/reframing typology established in the conceptual framework, there are two key themes which emerged over the course of the analysis which require consideration in order to facilitate the descriptive aspects of the analysis. The first and most pertinent theme which arose during the analysis was the blurring of conceptual lines between references to history, culture, and tradition. While many of the early programs made direct references to specific historical views or policy related to history, there is a marked decrease in these references after the first set of programs in 2002. While some references are still present, many of the programs shift their focus towards the cultural aspects 
and its relationship to preserving national identity. This results in a sharp increase in the number of references to culture, tradition, and national identity as well as the adoption of a number of interchangeable terms which combined them with history such as heritage, legacy, and values. Given the discursive shift towards 'populist nationalism' described by Wodak, it is unsurprising that these references have become more prominent as these parties have found electoral success. While these cannot be refences cannot be explicitly categorized as references to history, their context, which takes the form of an appeal to national identity, implies a connection to albeit in an indirect manner. Considering the fact that the conceptual lines between concepts like history, culture, and tradition become increasingly blurred over time, the analytical criteria of these sections assess whether or not the texts refer to history directly or indirectly and analyze them in this manner with respect to the research question.

The second theme examines the prevalence of the concept of Heimat which, as Wodak notes, persists throughout the existing body of far-right electoral programs in Austria. In German, the word Heimat can be loosely translated as "homeland" but there is no English equivalent which conveys the vast array of connotations specific to German culture, society, and statehood. In essence, it can be described as one's home and, by extension, includes the emotion, social and spatial connections associated with ones feeling of belonging. ${ }^{107}$ Heimat has existed in German cultural discourse since the $19^{\text {th }}$ century but its wide conceptual bounds have left it up for interpretation and victim to instrumentalization by various political actors. This has lead to significant shifts in its associated connotations across countries and over time.

${ }^{107}$ Celia Applegate. A Nation of Provincials: The German Idea of Heimat (Berkeley, CA: University of California Press, 1990) 2-3 
While Heimat is a multifaceted concept which contains a multitude of political, cultural, and geographic dimensions, the timeline and scope of this thesis limit its conceptual bounds to its usage within a contemporary politics context. In the context of far-right politics, Heimat has generally been conceptualized as a call for the active preservation of German culture through appeals to a patriotic sense of national identity, unity, and belonging. This is generally associated with the National Socialist conception of Heimat which utilized its emotional, cultural, and political connections to mobilize people against the perceived threat of an external other. In the postwar period, Heimat has generally been used by the far-right as a means to evoke emotional responses from voters but its meaning has begun to change in recent years. While Heimat was traditionally utilized to appeal for the preservation of the state within a liberal framework, scholars note that it has transformed into an exclusionary right to the 'homeland' which justifies the xenophobia by arguing that national identity must be protected. ${ }^{108}$ Consequently, this analysis will examine the role of collective memory in the exclusionary conceptualization of Heimat in accordance with previous work on far-right discourse.

\section{Analysis}

The use of references to history which address history, culture, and tradition is evident in the vast majority of FPÖ platforms as they have routinely combined these concepts in their electoral programs since 2002. Early FPÖ platforms, namely those from before 2002, contain a combination of direct and indirect references to history which are often weaved into positively framed arguments about pride in history, culture, and national identity along with calls for citizens to take pride in their heritage:

\footnotetext{
108 Reinhold Gärtner. "The FPÖ, Foreigners, and Racism in the Haider Era," in The Haider Phenomenon eds. Ruth Wodak and Anton Pelinka (New Brunswick, NJ: Transaction Publishers, 2002)
} 
The identity of Austria is characterized by a diversity and variety of regional identities, the people of Austria, after suffering painful historical experiences, have expressed their willingness to belong together in a framework of regional autonomy. The historical and cultural heritage of Austria entitles one to pride in its achievements and traditions [...] This includes pride in pan-German history, the rejection of policies which attempt to level culture at the expense of Austria peculiarity. ${ }^{109}$

In this passage, FPÖ emphasizes both the achievements and the hardships of the Austrian people through direct references to history framing them positively and appealing to collective memory as a means to evoke an emotional response. While the call for pride in pan-German history is reminiscent of some neo-fascist discourse, its inclusion is not particularly unusual in the context of Austrian politics. In contrast to the German programs, FPÖ's contemporary party discourse, despite some controversial comments by party members, was never associated with neo-fascism and therefore does not make the same type of direct appeal to the collective memory of Germany's defeat that parties like NPD adopted during this period.

FPÖ adopted a more liberal position in the early 2000s which included recognition of minority populations with historic ties to Austria. The basic premise of this association is based primarily on a direct reference to the historical significance of these groups within the Austrian nation:

"Homeland means the democratic republic of Austria and its federal states, the historically resident ethnic groups (Germans, Croats, Roma, Slovaks, Slovenes, Czechs, and Hungarians) and the culture that they have shaped, whereby the legal system presupposes logically that the vast majority of Austrians belong to the German ethnic group. ${ }^{110}$

This particular construction of the Heimat principle represents an interesting approach which essentially adopts a liberal approach to the preservation of majority culture. FPÖ routinely makes direct and indirect references to the collective memory of the Austrian nation but also argue that

\footnotetext{
${ }^{109}$ Freiheitliche Partei Österreich (2002). Wahlprogramm FPÖ 2002 'Wir gestalten Österreich mit Sicherheit' (Election campaign manifesto). Vienna. Ch.4, Paragraph 2

${ }^{110}$ FPÖ 2002, Ch.4, Paragraph 1
} 
historically resident ethnic minorities within Austria arguing that they are crucial components of society at large. This represents a direct appeal to history which both appeals to the collective memory of resident ethnic groups by integrating their culture into the process of preservation.

Unlike Germany, the concept of Heimat had already been well-established in FPÖ's electoral programs long before the established timeline of this thesis. As Meret notes, the concept of Heimat evolved considerably over the course of the past two decades despite being a key component of FPÖ's ideology. ${ }^{111}$ In what seems to be a reflection of its instrumental presentism (it is a concept based in collective memory) Heimat has often been adapted to fit FPÖ's current political circumstances over the years but since 2008 it has been established as an exclusionary right to ones homeland. The discursive changes this concept has undergone combined with its connection to collective memory indicate that it could provide valuable insight into how FPÖ makes reference to history through its electoral platforms.

The use of Heimat is a key part of FPÖ's early platforms with multiple chapters of their 2002 electoral program dedicated solely to explaining the concept. Interestingly, FPÖ espoused a quasi-liberal conception of Heimat at this point in time which not only argued for the but extended the right of "homeland" to ethnic minorities who had long-standing connections to the Austrian nation as a whole:

"Homeland" means the democratic republic of Austria and its federal states, the historically resident ethnic groups (Germans, Croats, Roma, Slovaks, Slovenes, Czechs and Hungarians) and their culture, whereby the legal system presuppose logically that the vast majority of Austrians belong to the German ethnic group. "Home" is conceptualized in spatial, ethnic, and cultural terms and the cultural traditions of all groups should be preserved. The free confession of the respective ethnic group is a basic condition for the preservation and further

\footnotetext{
${ }^{111}$ Meret Susi. "The Danish People's Party, the Italian Northern League, and the Austrian Freedom Party in a Comparative Perspective: Party Ideology and Electoral Support." PhD diss., SPIRIT PhD Series. 25. University of Aalborg, 2010. ISSN 1903-7783. 197
} 
development of cultural values and the historico-cultural understanding of each ethnic community.

Every Austrian has the fundamental right to be self-determined and free about his identity and nationality. They must not be disadvantaged by their ethnicity, but they can only derive subjective rights from historically established groups and Austria. The state does not have the right to regulate or determine which view of itself a citizen takes. ${ }^{112}$

These passages demonstrate the basic premise of Heimat as it exists in FPÖ's ideology by describing the concept, delineating the groups it can be associated with and making the case for its intrinsic connections. FPÖ essentially argues for the practice of politics through a historicocultural lens which actively acknowledges the historical, cultural, and traditional aspects of both majority and minority communities as long as they have long-standing connections with the existing nation. Interestingly, the categorization of certain ethnic minorities as "historically resident" seems to harken back to the days of the Austro-Hungarian Empire

The use of Heimat is not simply an abstract notion however can be used to rationalize certain policies through the extolling of exclusionary rights to specific members of an ethnic community. FPÖ's use of Heimat does not simply profess the preservation by individuals but calls for opposition to any policies which could be conceived as a threat to social stability:

Especially on the medial level, cultural flattening has been recognizable for years; this requires new intellectual and cultural departure in order to keep Austrian traditions, peculiarities, and regional characteristics alive. ${ }^{113}$

This passage reveals the means by which FPÖ integrates direct and indirect references to history into the existing framework of Heimat. They first argue that the historical, cultural, and traditional aspects of Austria are under threat and then instrumentalize this argument to advocate for exclusionary policies such which oppose immigration or multiculturalism in general. This

\footnotetext{
112 FPÖ 2002, Ch. 4 Paragraph 1-2
}

${ }^{113}$ FPÖ 2002, Ch. 3, Paragraph 4 
represents the basic discursive technique of direct and indirect references to history in the context of Heimat in FPÖ's programs although this would change significantly over the course of time.

Unlimited immigration would overburden the local population with regard to their ability to integrate actively, thereby jeopardizing the right to protection of their own "homeland." Multicultural experiments are rejected due to their tendency to deliberately fuel social conflict. ${ }^{114}$

Interestingly, the electoral programs for the 2006 and 2008 elections contain little to no references to Heimat or any overtures to its core principles. But, as Meret notes, FPÖ published a number of supplementary materials which engaged in profound discussions Heimat and seeks to clarify its deeper meaning with respect to history, culture, and identity. ${ }^{115}$ For example, in the Manual of the Freedomites' Politics, there is an entire chapter is dedicated to the party's position on preserving national identity all of which is based on the concept of Heimat. ${ }^{116}$ Although these could provide some insight into the workings of FPÖ's historically-based rhetoric, they are outside of the scope of this thesis and therefore cannot be subject to the criteria of this discourse analysis which has been specifically designed to explore references to history in electoral programs. Scholars who study this subject in the future however should consider these materials for more comprehensive studies.

The concept re-emerges in FPÖ 2013 electoral program and although the argumentation is somewhat limited, it represents the re-integration of the concept into their electoral programs. In this case, FPÖ utilizes an indirect reference to history which, in this case, is referred to as Austrian identity, agues that it is a combination of the encroachment of radical Islam and the inability of other parties to confront it which threaten Austrian history, culture, and tradition:

\footnotetext{
114 FPÖ 2002, Ch. 4, Paragraph 4

115 Meret 197-198

${ }^{116}$ Meret 198-199
} 
SPÖ, ÖVP and the Greens do not protect Austrian identity enough. With the EU, they work to establish a unitary state and a unitary people. They encounter radical Islam with false tolerance and cowardice. One gets the feeling they are ashamed of their own culture and traditions. We want to preserve our own identity. For us, our traditions, customs and culture are unique and deserve to be protected. This includes our language as well as rule of law, democracy or the separation of church and state. Therefore, we demand: No place for radical Islam; stop migration from outside Europe; stop ESM guarantees; no to Turkey's accession to the EU; promotion of the German language especially in the publicly funded media; commitment to our language and our values as a prerequisite to obtaining citizenship. ${ }^{117}$

In this passage, FPÖ adopts a confrontational tone which clearly frames both the opposition appealing to collective memory by pointing their inability to enact the principles of Heimat and defend Austrian history, culture, and tradition from the encroachment of "others" which they argue is radical Islam. The references are indirect and are used to rationalize the argument and form the basis of some of the policies that it seeks to achieve. Moreover, they instrumentalize the references to history through a confrontational tone to advocate for the adoption of a smattering of policies including immigration, citizenship, and various EU integration initiatives. While there is no consistent direction to this instance of Heimat instrumentalization, the readoption of Heimat in FPÖ's 2013 electoral platform represents a significant discursive shift away from their previous tendency to shy away from references to history.

The 2013 Austrian federal election saw FPÖ return to referencing history, culture, and tradition in their electoral programs albeit in a more limited capacity. Where FPÖ once included in-depth discussions of and predicated their arguments on a number of indirect references to history, their 2013 program limits these arguments to a single page in their program where they state their intentions for cultural policy: "What does FPÖ want to do? Traditions, customs, and culture are unique and worthy of protection. This includes language as well as our rule of law, democracy, and the separation of church and state." ${ }^{118}$ While the argumentation is much more

\footnotetext{
${ }^{117}$ FPÖ 2013 Slide 11

118 Freiheitliche Partei Österreich (2013). Wahlprogramm FPÖ 2013 (Election campaign manifesto). Vienna. Slide 11
} 
direct than previous platforms, one does see FPÖ make indirect appeals to history which not only combines aspects of tradition, culture, and customs but argues, through an appeal to collective memory, that they are the fundamental building blocks of the key institutions which make up Austrian society. It is worth noting that despite the limited use of these references when compared to past programs, FPÖ's 2013 program is only twelve pages long with one of those twelve pages dedicated to making these cultural arguments.

In contrast to their 2013 electoral program, in which they point to specific threats to the preservation of Austrian history, culture, and tradition, FPÖ take a more generalized approach in their 2017 electoral program which places the preservation of as one of the central aspects of their cultural platform and strikes an imperative tone that calls voters to exercise their exclusionary right to the homeland by preserving history, culture, and identity:

In a period of identity destruction and alienation of people from their roots in the interests of global corporations and global financiers, attention must be paid to the ideological commitment to the preservation of their own cultural heritage and language $[\ldots]$ The preservation of identity is the conscious theme of our era. It succeeds only by actively developing and continuing the tradition. ${ }^{119}$

FPÖ's 2017 electoral program takes a more imperative approach to the instrumentalization of history, culture, and identity presenting a sort of balance between a confrontational tone which decries the threats to cultural, history, and traditional while also adopting a positive tone which lauds the nation's achievements and calls for its protection. It appears as though they combined the two approaches into a more balanced discursive technique which appeals to both the extreme and moderate views on cultural issues. In contrast to the antagonistic stance they took in previous

\footnotetext{
${ }^{119}$ Freiheitliche Partei Österreich (2017). Wahlprogramm FPÖ 2017 'Österrereicher verdienen FAIRNESS. (Election campaign manifesto). Vienna. Slide 5
} 
writings, they portray more of an imperative argument demanding action from voters to actively engage in the preservation of history, culture and tradition.

In their 2017 electoral program, FPÖ also continued their limited use of indirect references to history, culture, and tradition. This time however, FPÖ makes a conscious effort to present the preservation of those concepts as a key part of their mandate: "The preservation of identity is the fundamental theme [Gewissensthema] of our era. Yet the preservation of identity succeeds only by actively developing and continuing tradition." ${ }^{120}$ Here, FPÖ frames the argument not in a confrontational sense as they did in previous platforms but an imperative one. There is no blame placed on particular groups or political parties and it is simply an appeal to collective memory which evokes emotional responses from generalized notions of which is meant to be interpreted by the reader. This, of course, could be categorized as a sort of "coded" discourse which allows one to make their own exclusionary conclusions. While this program places less emphasis on direct and indirect references to history in general, the ones it does use re-integrate the positive framing of Austrian history, culture, and tradition which is present in their earlier programs

\section{Results}

This analysis of FPÖ's electoral programs has produced a number of useful insights with respect to the means by which far-right parties make reference to history. With respect to the research question, the most pertinent finding of this discourse analysis was the consistent use of indirect reference to history throughout FPÖ's electoral programs. Aside from some assertions about the electoral claims of indigenous minority groups in their early platforms, FPÖ's

${ }^{120}$ FPÖ 2017, Slide 5 
argumentation is based primarily on the positive framing of indirect references to assert the value of history, culture, and tradition to justify certain policy positions which "preserve" the majority culture. Much like AfD, FPÖ often makes overtures to the positive elements of Austria's history, culture and tradition while arguing that they are intrinsically connected to the institutions which govern Austrian society. This is done through blanket statements which refer to various combinations of history, culture, language, tradition, or customs together or the use of interchangeable terms like cultural heritage. These arguments are contained within the framework of Heimat which utilizes these "coded' arguments to justify exclusionist policies.

In terms of the established typology, it is clear that FPÖ has engaged in a reframing approach to references to history for the majority of the chosen timeline. These types of references have increased in magnitude over time and resulted in a decrease in direct references to history in favour of indirect references which reframe them in a manner that suits FPÖ's nationalist rhetoric. While there were some direct appeals to history in their early platforms, many of them were presented in a "coded" manner which reframed the arguments so that they do not revise history but present certain aspects of it in a manner which is compatible with their views. It should be noted that FPÖ did not engage in revisionist discourse and there is little mention of National Socialism other than vague appeals to a "difficult past" but, even then, it is reframed to inspire pride in the Austrian people for enduring such adversity. The consistent use of reframing strategies is thus consistent with the observations of scholars like Riesigl and Wodak and allows Austria to be used as a comparative model for the adoption of reframing strategies by the far-right.

With respect to the general trends in discourse, the use of indirect historical references in FPÖ's electoral programs is somewhat limited after their 2002 programs. While this may seem to 
indicate that the frequency and magnitude of references to history and even Heimat itself have decreased over time, it possible that this is a quirk of FPÖ's process of external communication given their tendency to publish supplementary materials which directly address key ideological aspects of their platforms. It is also possible that emergence of "coded" exclusionary discourse in electoral program as described by Wodak may have led to FPÖ expressing their views more openly through other mediums but further research on FPÖ's other political texts is needed to confirm this conclusion. At the same time, FPÖ's reluctance to make reference to history, culture, and tradition or make appeals to collective memory in their electoral programs does demonstrate a clear when compared with other parties making FPÖ's situation unique to the peculiarities of the Austrian political discourse. 


\section{V: Germany}

"Cultures, languages, and national identities have been formed through centuries of historical development. They represent an indispensable identification space for those who belong to them which can only be effectively filled with life in national states with a democratic constitution. Only here can people's sovereignty - the mother and the heart of democracy-be lived."

- AfD Electoral Program (2017)

The following chapter will consist of an analysis of the electoral programs of AfD, NPD, and FPÖ based on the Discourse-Historical Approach organized in the same way as the preceding chapter. Over the course of this analysis, the same two key themes which emerged in the Austrian portion of the analysis are present throughout the majority of the texts for Germany's far-right parties and will thus be considered alongside the established revisionist/reframing typology. In terms of structure, the party programs are described chronologically beginning with NPD in 2002 and proceeding until the most recent elections in 2017. Passages from these texts containing references to history will be described, analyzed, and comparatively analyzed in an intertextual perspective and draws conclusions based on the established categories, themes, and typology.

\section{Analysis}

The discursive shifts with respect to references to history, culture, and tradition throughout the electoral platforms were, in the case of Germany, a gradual process which saw established far- right parties like NPD pivot away from overtly neo-fascist notions of revisionist history and towards a more generalized appeal to collective memory which skirted the negative historical connotations of the party's association with National Socialism. By blurring the lines between history, culture, and tradition, and making broad appeals to collective memory which 
voters were more willing to accept, NPD was able to instrumentalize their existing appeal to collective memory and justify its policies without reverting to unpalatable arguments which stir up memories of national socialism.

This shift in discursive focus is clearly visible in NPD's electoral programs from 2002 to 2009. In their 2002 electoral program, NPD utilizes overt references to history and Nazi-era language clearly represent an appeal to the collective memory which is based on National Socialist roots. For example, the opening line of the 2002 electoral program evokes: "Volkstum and culture are the foundations of human dignity. That is why the state, whose task is the protection of human dignity bears responsibility for the people. The people are carriers of culture and they differ in language, origin, historical experience, religion, and values." ${ }^{\prime 21}$ The use of the term Volkstum (folklore) is particularly striking in this context of an electoral program due to its connections National Socialism. While the term generally refers to the collective memory of the German nation, it was interpreted aggressively in Nazi writings where it came to be associated with notions of "racial consciousness." Although there are some direct appeals to neo-fascistic conceptions of collective memory through the use of specific words, one can see evidence of the lines beginning to blur in this passage through the connection of similar concepts such as culture, history and tradition in conjunction with an appeal to indirect references to history used. The appeal to collective memory is thus, in a general sense, predicated on a combination of all these concepts as products of history and key components of national identity. Through asserting that the people themselves are carriers of these things, NPD are able to utilize indirect references to

\footnotetext{
${ }^{121}$ Nationaldemokratische Partei Deutschlands (2002). Wahlprogramm NPD 2002 'Ein Programm für das Volk!' (Election campaign manifesto) Berlin. 2-3
} 
history to evoke an emotional response and argue that since their party are the only ones who truly understand these intrinsic connections, they are the best candidates to defend them.

Aside from basic appeals to history, culture, and identity throughout their preamble and at various points in the introductory paragraphs, NPD dedicates a significant portion of their electoral platform to addressing historical issues specifically. The references to history in this section are explicitly stated, rife with historical revisionism, and appeal to the traumatic collective memory of the German defeat in World War II. While this section does contain overtly neo-fascistic discourse which is based on historical revisionism, it does not glorify or, even mention, National Socialism but frames the argument in a way which paints Germany as victims of the Allied victory who are now held back by a "culture of guilt." The basic premise of their historical views is described in the opening passage:

A people without a past has no future. For the sake of its future, Germany needs a national view of history that focuses on the continuity of our people. We defend ourselves against the moral self-destruction of our nation by the one-sided blame at the expense of Germany, the appreciation of treason and the glorification of Allied war crimes. We therefore demand the protection of the honour of the German people including the ostracism of history and an end to one-sided coping with the past. We Germans are not a nation of criminals. ${ }^{122}$

Here, one sees NPD make a direct appeal to history by negatively framing Germans as the victims of an oppressive post-war consensus which deprives them of the ability to celebrate their history. Having already argued that a nation's history, culture, and tradition are fundamental components of human dignity and the building blocks of a well-functioning society, NPD engage in an appeal to collective memory which attempts to break the existing norms of the established memory culture. NPD continues its historical section by making a series of specific demands which are directly connected to their revisionist views of German history:

122 NPD 2002, 9-10 
Germany in its historically grown borders. The restoration of Germany is not achieved with the union of the occupation constructions FDR and GDR because Germany is bigger than the Federal Republic! [...] The unconditional surrender of German territories, which ignores our history and violates international law, can not be accepted. We consistently insist on a just and lasting peace settlement. The world of states rearranges itself and as part of this reorganization, Germany must - in accordance of international law and the Helsinki Agreement - pursue a peaceful policy of reunification within its historically grown borders. In the meantime, there is a duty to help millions of Germans in the separated areas to preserve their German culture and national identity.

We demand a confession of our former opponents that the targeted bombing of the civilian population, the expulsion of millions of German civilians after the war, and the killing of German prisoners of war are crimes that still must be punished today [...] In the field of culture, we are committed to the protection of our cultural heritage from distortion and falsification. Therefore, history teaching should no longer serve as a guideline but must be made to comprehensively project the entire history of our people. ${ }^{123}$

This passage demonstrates NPD's penchant for historical revisionism as they are utilizing direct references to history which are based on appeals to the collective memory of National Socialism. While they do not mention, elaborate on, or advocate for National Socialism in any way it is clear that the similarity of these demands with traditional neo-fascist discourse is an attempt to produce a "coded" position in the form of a rational argument. These passages highlight the tendency of NPD to utilize direct references to history which, through negative framing and association with collective trauma, attempt to capture voters through appeals to the collective memory of Germany's memory culture.

While it has largely remained dormant in the post-war era, the concept of Heimat appears to have expanded into German far-right discourse as it is present throughout the electoral platforms of both NPD and AfD. Each party embraces the basic premise of the concept as an exclusionary right for a nation to preserve ones history, tradition, but adapt the concept to meet their own strategic needs. Moreover, each party makes use of direct and indirect references to

${ }^{123}$ NPD 2002, 10-11 
history in different ways choosing to adopt different types of framing, language, and policy priorities depending on their circumstances. The first evidence of Heimat is present in NPD's early electoral programs which utilize the concept as the guiding premise for their type of politics:

Peoples [Völker] support cultures. Peoples differ in their language, origin, historical experience, religion, world views and consciousness. Peoples realize their uniqueness especially when and where they are endangered. Preserving peoples means preserving culture. Mere societies do not develop a culture, but at best a civilization whose highest values are materialist. "Multicultural" societies are in reality societies without culture. The diversity of peoples must be preserved.

A people's form of political organization is the nation state, in whose confines a people fosters its values, ensures its safety, secures its future, and protects the material preconditions of its life. Germany is the country of Germans and thus the homeland [Heimstatt] of our people. The preservation of our people and the protection of all of its parts are the supreme goals of German politics. For this purpose, the German people aims at friendship and good relations with all well-meaning nations, in order to fight together against the destruction of the foundation of life through multicultural, imperialist and levelling forces. ${ }^{124}$

This passage presents the conceptual basis for NPD's take on the concept of Heimat which they interpret as a manifestation of the angst which emerges when a nation's history, culture, and traditions are under threat. Since they categorize history, culture, and tradition as key factors in the functioning of the state, NPD argue that their preservation is the goal of all German politics, a goal which only they understand. Their conception of Heimat utilizes the existential threat of multiculturalism as a coded means for the justification for their exclusionary policies.

After opting not to produce an official electoral program for the 2005 federal election but attaining a relatively promising $1.8 \%$ of the vote, NPD appears to have attempted to modernize its electoral program to broaden its appeal among voters. While their 2009 electoral program still contains extremist policies, which can be considered to be neo-fascistic in nature, many of the

${ }^{124}$ NPD 2002, 2 
overt direct or indirect references to history have been eliminated in favour of a more policyfocused platform. Looking at the structure of the program, NPD limits their references to history, culture, and tradition to scattered parts of their introduction as well as the preambles to certain sections depending on the context. In general, the direct and indirect references to history are contained within a general section on the party's cultural policy. For this program, the basic premise of their historical arguments can be gleaned from this passage in the introduction: "The Volksgemeinschaft was destroyed in Germany. It was replaced by an increasingly multicultural collection of individuals pursuing selfish ends. More and more Germans are finding no foothold in the community of their family or neighbours." ${ }^{125}$ Once again, NPD continue to utilize National Socialist era language.

However, where NPD once focused on neo-fascist discourse making direct appeals to revisionist forms of history and evoking memories of their past trauma, they shift their focus towards the domain of culture in their 2009 program by choosing to focus on a generalized view of history, culture, and tradition:

In addition to schooling on general matters and science, schools should put an emphasis on regional issues in order to teach children attachment to their homeland [Heimat] and people [Volk], identity, and customs. [...] In history lessons, the pupils should be given a historically objective picture of the past of their own people - without the currently fashionably, onesided cult of guilt. ${ }^{126}$

This passage demonstrates a significant shift in NPD's discourse on the subject of history. In their earlier programs, NPD would often attempt to conjure up appeal to the collective memory through direct appeals to Germany's defeat and the perceived "oppression" of the Allied victors who imposed a culture of guilt. In terms of substances the general argument that Germany's

\footnotetext{
${ }^{125}$ Nationaldemokratische Partei Deutschlands (2009). Wahlprogramm NPD 2009 'Deutschlands starke Rechte' (Election campaign manifesto) Berlin. Slide 6-7

${ }^{126}$ NPD 2009, Slide 33-34
} 
history is a victim of memory culture is similar, but arguments are the 2009 electoral program adopt a different discursive approach. Direct historical references to the Nazi past and grandiose neo-fascistic policy demands have all but disappeared in favour of more generalized references. NPD does, however, maintain the victimhood narrative through the use of negative framing portraying German history, culture, and tradition as victims of "distortion" which can only be remedied by changes to history curricula.

NPD's 2013 platform is puzzlingly moderate in comparison to the rest of the programs examined as part of this analysis. It is largely policy focused and reminiscent of an electoral program from a mainstream political party. Consequently, it is missing many of the traditional elements In this program, the only references to history, culture, and tradition are contained with a specific cultural section which frames the cultural discussion about preserving culture heritage as a policy issue:

In the area of culture, we commit to protecting our rich cultural heritage against distortion, falsification and sell-off. The NPD wants to put the national cultural heritage under the explicit protection of the state; a Federal Culture Council should in the future be able to intervene if cultural heritage is presented in a distorting, obscene, or defacing fashion. German cultural heritage must not be appropriated as "world heritage" by supra-state agencies. Notwithstanding the federalist traditions of our country in the field of culture, we see a need for centralized regulation of state support for film and art, as well as media policy. We do not accept a right [for the media] to report in a tendentious and vilifying fashion - not even with reference to the rights to free speech and to a free press. These rights find their limits where basic values of Western tradition like homeland [Heimat], family and religion are slandered, where the mass media is abused for political purposes, and where the public space is turned into a projection screen for obscenities. ${ }^{127}$

In this passage, NPD makes references to culture heritage which can be categorized as an indirect reference to history, but its presence is purely instrumental, and is not party of any sort

\footnotetext{
${ }^{127}$ Nationaldemokratische Partei Deutschlands (2013). Wahlprogramm NPD 2013 'Natürlich Deutsch' (Election campaign manifesto) Berlin. 61-62
} 
of argumentation. NPD simply makes a straightforward argument that there is too much state control of culture by "others" who are perceived as working against the interests of German culture, tradition, and history. Consequently, they propose a policy to address it in which they exert control over a wide variety of cultural institutions with the goal of preserving their culture. In addition to these demands for changes in cultural policy, NPD also repeats several of the arguments from its 2009 platform on the teaching of more "objective" German history, but their arguments are largely unchanged and there are no notable shifts in discursive technique other than the policy-focused structure.

After a disastrous electoral showing in the 2013 federal election, the emergence of AfD seems to have pushed NPD to forsake their moderate turn and pivot towards adopting a narrower focus on anti-immigration in order to consolidate their support among voters who believed AfD was too moderate in their policy demands on migration. This strategy proved effective for NPD in the past especially during the 2005 election when their shift away from a more comprehensive electoral program correlated with a margin of $1.8 \%$ of the vote, a relatively successful result for a fringe far-right party. Consequently, their 2017 electoral program, aptly named Heimat verteidigen (Defend Home), fully embraces an exclusionary anti-immigration focus by appealing to collective memory through framing history, culture, and identity as being "under attack" by mass-immigration:

Population growth in the Middle East and in Africa leads to migratory pressures with which European states, as they are currently constituted, cannot cope. Germany and Europe must become a fortress if they wish to preserve their identity and to protect themselves against an avalanche of migration that threatens their existence. Only a fortress Europe can secure peaceful mobility within it. [...] The present program deals with existential questions that cannot be put off any further. It contrasts the political will of the NPD with the political activities of the established parties, which are in the process of destroying the future of our 
people. We are not a party that curries favour with the large parties and hopes for partnership in a coalition. ${ }^{128}$

In stark contrast to their 2013 electoral program, NPD adopts a much more confrontational mode of argumentation focusing completely on immigration issues. The 2017 electoral programs represent a significant shift in discursive strategy which brings the focus back towards cultural issues albeit within a narrower conceptual focus. Interestingly, there is a marked decrease in the use of references to history, culture, and identity other than as their conceptual focus is narrowed to negative framing of history, culture, and identity as victims of immigration.

Despite the adoption of a moderate platform in their 2013 electoral program, NPD retains the vast majority of their cultural views and builds on the concept of history, culture, and tradition under threat by tying it to specific forms of social strife and instrumentalizing those ideas to argue for an exclusionary right to the homeland both figuratively and legally:

The supreme reference point for NPD politics is the responsibility for the survival and continuity of the German people in its traditional Central European habitat. In accordance with the provisions of the UN Charter, we firmly reject mass immigration and change to the ethnic majorities in urban agglomerations of our country, which represent an attack against the integrity and identity of our people. ${ }^{129}$

In this passage, NPD frames indirect references to history in the form of identity, values, and character as key aspects of their culture which are under threat and all of the references used are contained within the exclusionary framework of Heimat. Moreover, the begin to associate with specific phenomena which many attributes to the advent of globalization including social strife, unemployment, and crime. By identifying specific aspects of history tradition, and culture that are under threat and connecting them with problematic prominent social issues, NPD utilizes

\footnotetext{
128 Nationaldemokratische Partei Deutschlands (2017). Wahlprogramm NPD 2017'Heimat Verteidigen' (Election campaign manifesto) Berlin. Slides 4-5

${ }^{129}$ NPD 2013, 41
} 
historical references in an attempt to make an argument against immigration and ethnic change specifically.

In their 2017 electoral program it is clear that NPD adopted an extreme form of Heimat which is solely focused on the threat of immigration and frames their references to history, culture, and tradition as a means to emphasize the active threat of immigration to Germany:

Right now, can be called a crossroads. If the mass immigration of recent years continues unabated, Germany will no longer be recognized in just a few years, and future generations of Germans will live as a minority in the land of their ancestors. [...] We do not want Islamization, population exchange, multi-cultural experiments or mass immigration - it is now necessary to organize political self-defence. It is our country and it is high time to bring it back to us. ${ }^{130}$

While there are many other passages like this one in NPD's 2017 electoral platform, this passage from the opening paragraph demonstrates the extreme extent to which NPD has embraced the exclusionary aspects of Heimat. Unlike their previous platforms, there is no in-depth discussion of history or culture, no description of the virtues of the nation-state, and only limited framing in a negative context. The indirect references to history and appeal to collective memory are contained solely within the context of the exclusionary right of Heimat and are not utilized in any other way throughout the program. The language is highly confrontational and, in some cases, derogatory as immigration and immigrants themselves are framed as an active threat to German society instead of abstract concepts such as multiculturalism.

It appears that in the face of stiff competition from AfD, NPD have taken a contrasting approach which defaulted to the lowest common denominator by taking an extreme position on the exclusionary right to Heimat In general, it seems NPD has abandoned its tendency to utilize direct and indirect references to history but their decision to narrow its conceptual focus and

${ }^{130}$ NPD 2017, Slide 3 
dedicate its efforts to the exclusionary aspects of Heimat provides insight into the contrasting methods of far-right discursive techniques and the significance of historical references as a whole.

While NPD is a firmly established party in German far-right politics, AfD is a relative newcomer to the scene who has challenged existing far-right parties by adopting different discursive techniques. When AfD first entered the German political scene, they were composed primarily of a group of disgruntled conservatives who had become frustrated over CDU/CSU's handling of the Eurozone Crisis and the lack of an outlet to oppose the EU at the federal level. After publishing manifesto which was endorsed by several prominent economists, journalists, and business leaders, they decided to create a party to compete in the 2013 election. At the time of its founding in 2013, AfD was conceived as a centre-right conservative party espousing a form of 'soft' Euroscepticism which opposed both the Euro and further European integration. ${ }^{131}$ There were however, two distinct factions within AfD emerged both of whom had different visions for the future of the party, led by Bernd Lucke who focused on economics and the other led by Frauke Petry who focused on anti-immigration policy. Over time, factional infighting combined with volatile public debates about the Migrant Crisis led to Lucke's departure from AfD and the ascension of Frauke Petry as leader. In the context of this analysis, the shift from moderate to radical conservatism in such a short time means as well as the circumstances of their entrance have had a significant effect on the content of their electoral programs.

While their 2013 electoral program focuses primarily on issues of economics, AfD's 2017 electoral program takes a much different approach which is based primarily on positive

${ }^{131}$ Stijn van Kessel. Populist Parties in Europe: Agents of Discontent? (London: Palgrave MacMillan, 2015) 61-62 
framing of direct and indirect references to history. In contrast to NPD, who became less reliant on historical references over time, AfD made them an integral part of their argumentation. Instead of portraying Germany as the victims of history, AfD sees German society as an extension of the underlying historical, cultural, and traditional currents of Western civilization which have helped build the institutions of liberal democracy. Through positive framing of direct and indirect references to history, they portray German culture as a product of those virtues and instrumentalize that idea as part of their appeal to collective memory. These two passages serve as examples of how AfD express these ideas throughout their electoral platforms:

The principles of equality before the law and bourgeois freedom of contract are among the great civilizational achievements of Europe. Throughout much of human history, it was part of the unquestioned normality that humans were unequal in birth, status, and legal selfdetermination relegated to lawlessness in the form of serfdom or slavery. It was the Christian and humanistic culture of the European peoples who first brought forth and realized the principles above (equality under the law) through a centuries-long process.

The AfD is committed to the German leading culture. This is based on the values of Christianity, antiquity, humanism, and the Enlightenment. In addition to the German language, it also includes our customs and traditions, intellectual and cultural history. Our liberal constitutional state, our appreciation of education, art, and science and the social market economy as an expression of human creativity. ${ }^{132}$

These passages demonstrate further evidence of the use of positive framing in AfD's references to history, culture, and tradition and their tendency to draw on a wider body of historical references than other far-right parties. While other far-right parties tend to frame their nation's achievements, AfD's references to history, culture and tradition tend to draw on a broader range of historical references and connect them to German culture. These include references to humanist, Christian, and Enlightenment traditions, all of which AfD argues are the basis for German history, culture, and tradition. This process is used as part of their positive framing and

\footnotetext{
${ }^{132}$ Alternative für Deutschland (2017). Wahlprogramm AfD 2017 'Program für Deutschland' (Election campaign manifesto). Berlin. 46-47
} 
emphasizes the intrinsic connections of German culture to key aspects of liberal democracy.

Their process of argumentation involves making a positively framed historical argument which does not necessarily profess the superiority of German culture but argues for its positive aspects and connects them with the certain aspects of history, culture, and tradition that they argue must be preserved. These references, combined the connections that AfD establishes, are then used to justify certain policies or views.

In contrast to NPD's increasingly extremist and exclusionary discourse, AfD adopts a more nuanced approach to the practice of Heimat which engages in a combination of and positive framing of history, culture, and tradition with the goal of justifying exclusionist policies. These arguments are based primarily on AfD's assertion that the positive achievements of German history, tradition and culture are all jeopardized by multiculturalism due to the irreconcilable differences between cultures:

"Multi-culture" is non-culture or parallelism of cultures and thus expression of parallel societies, which always leads to domestic conflicts and the inability of states to function. The civil societies of functioning states are therefore called upon to protect their cultures and develop them independently. Of course, this also applies to German cultural identity. The cultural struggle between the Occident and Islam, which is already taking place in Europe as a doctrine of salvation and as the bearer of non-integratable cultural traditions and legal prescriptions, can only be averted by a package of defensive and restrictive measures that prevent further destruction of European values of living together as enlightened citizens. The AfD will not allow Germany to lose its cultural face due to misunderstood tolerance.

Many Muslims live lawfully (and integrated) and are valued members of our society. However, AfD wants to prevent the spread of secluded Islamic parallel societies in which Muslim "peace judges" apply Sharia law and undermine the state monopoly on prosecution and jurisdiction. The AfD fully recognizes freedom of belief but it demands, however, that the exercise of religion [should be limited] by state laws, human rights, and our values. Public law in the secular state is about religious commandments and traditions. Criticism of Islam, religious satire, and cartoons are legal under general laws. They are an outflow of the fundamental right to freedom of expression and artistic freedom. ${ }^{133}$

${ }^{133}$ AfD 2017, 46-47 
These passages demonstrate the fundamental basis of AfD's discursive technique of utilizing references to history, culture, and tradition within the framework of Heimat. In this case, they do not necessarily blame immigrants themselves, but connect the issues with integration of migrants into German society as a product of a long-standing civilizational conflict which pits historical and cultural values in an unreconcilable situation. In contrast to NPD, AfD does not utilize derogatory, or imperative language but attempts to portray its views as legitimate through indirect references to historical conflicts between two cultures which cannot be reconciled. Moreover, they argue that this civilizational conflict can only be remedied by adopting a set of policies which promote the majority culture and reject those which are incompatible.

The contrast between NPD and AfD's discourse is not simply a question of method, however, but reflects each party's relationship to the ideological underpinnings of far-right movements in contemporary Germany. The views expressed by AfD in this passage are largely reflective of Germany's New Right, a socio-political movement whose ideological current consciously distinguishes itself from the "old" neo-Nazi right by replacing overtly neo-fascist ideas with various forms of ethnopluralism. ${ }^{134}$ They are anti-immigration, anti-elitist, antipluralist and nationalistic but advocate for the achievement of cultural hegemony through "intellectual debate" within the established system in lieu of violence or revolution. Their core principles are based on criticism of multiculturalism, nationalistic conceptions of identity, opposition to immigration and contempt for the liberal constitutional order all of which have been thrusted into mainstream political discourse due to various crises affecting contemporary Europe.

134 Samuel Salzborn. "Renaissance of the New Right in Germany? A Discussion of New Right Elements in German Right-wing Extremism Today." German Politics and Society 34, No. 2 (2016) 37-38 
AfD's adoption of the ideological principles of the New Right can largely be attributed to the influence of Marc Jongen who is considered the party's chief ideologue. ${ }^{135}$ Jongen's philosophical works form the foundation of AfD's views and adhere to what historian Michael Weingarten calls a "völkisch" tradition with a Western-centric worldview based on the Christian tradition. ${ }^{136}$ However, many of his views and philosophical musings seem contrary to that view. In considering the party's position on migration, Jongen argued that their anti-immigration policies were meant to "correct the outmoded structure of European culture from the identity side" in response to mainstream political parties who do not understand the identitarian issues with migration. Jongen goes on to argue that migration is an "act of violence" against the "psycho-social integrity" of the German nation and his interpretation of immigration as an "invasion" is a prominent feature in the vast majority of AfD discourse. ${ }^{137}$ Jongen also argues that German cultural policy must be saved from "desecration" and has advocated on behalf of the party for the defunding of cultural organization which it feels are detrimental to the positive representation of German identity. ${ }^{138}$ Finally Jongen and has often advocated for recognition of "racism against Germans" by other political parties who refuse to acknowledge issues of national identity. ${ }^{139}$ It is clear from the passages described above that AfD has adopted many aspects of

\footnotetext{
135 “AfD-Vordenker Marc Jongen: Sloterdijk-Schüler auf Abwege." Handelsblatt [Retrieved September 5 ${ }^{\text {th }}, 2019$ ]

${ }^{136}$ Michael Weingarten. "Jongen: Vordenker der Umvolkung" In Kontext: Wochenzeitung. May $17^{\text {th }}, 2017$. Accessed September $5^{\text {th }}$, 2019. [https://www.kontextwochenzeitung.de/politik/320/jongen-vordenker-derumvolkung-4371.html]

137 Jens Jessen and ljoma Mangold. "Marc Jongen: "Man macht sich zum Knecht” Die Zeit - Online. May $25^{\text {th }}, 2016$. Accessed September $5^{\text {th }}, 2019$. [https://www.zeit.de/2016/23/marc-jongen-afd-karlsruhe-philosophieasylpolitik/komplettansicht]

138 "Theater wehren sich gegen Angriffe" Westfälische Nachrichten. January $14^{\text {th }}, 2019$. Accessed September $5^{\text {th }}$, 2019. [https://www.wn.de/Welt/Kultur/Buehne/3617822-Buendnis-Die-Vielen-Theater-wehren-sich-gegenAngriffe]

139 Maria Fielder "Fraktionen gehen hart mit AfD ins Gericht" Der Tagesspiegel - Online. February $23^{\text {rd }}, 2018$. Accessed September $5^{\text {th }}, 2019$. [https://www.tagesspiegel.de/politik/debatte-im-bundestag-fraktionen-gehenhart-mit-afd-ins-gericht/20998612.html]
} 
Jongen's ideological views but softened them through the integration of liberal Western-centric discourse with the help of references to collective memory.

The adoption of these key concepts keeps AfD in line with the intellectual undercurrents of the far-right politics and gives them the necessary ideological basis to craft nuanced discourse through the use of collective memory. In contrast, NPD has largely excluded itself from associations with the New Right and denounced the movement due to its willingness to work within established systems. This drew the ire of New Right groups and prominent figures such as Götz Kubitschek who denounced the NPD's strategy as “not living up to their self-imposed aspirations of advancing Germany." 140 The differences in discursive strategy throughout the electoral programs of both parties are reflective of this ideological divide with AfD being more representative of current far-right schools of thought. In terms of the discursive strategies themselves, AfD's intellectually-oriented method of presentation sets them apart from NPD and allows them to present what appears to be a more nuanced form of discourse which, through the use of collective memory, maintains the ambiguity necessary to appeal to a broad coalition of conservative voters. In contrast, NPD's more direct approach seems simplistic and invites negative mnemonic associations with the "old" neo-fascist right, a situation which the party has often sought to avoid for obvious reasons. It should also be noted that AfD's willingness to work within the system and adapt its views to reflect current schools of far-right though could be key factors in its success as a far-right populist party.

\footnotetext{
140 Mathias, Brodkorb. "Molau (NPD) will Alternative zur "intellektuellen Selbstbefriedigung" des IfS". ZEIT Online Blog Störungsmelder, May $9^{\text {th }}, 2008$. Accessed September $5^{\text {th }}, 2019$. [https://blog.zeit.de/stoerungsmelder/2008/05/09/andreas-molau-npd-will-eine-alternative-zur\%E2\%80\%9Eintellektuellen-selbstbefriedigung\%E2\%80\%9C-des-ifs-schaffen_302]
} 
One of the key differences between NPD and AfD's discourse is the magnitude and scope of their instrumentalization of references to history, culture, and tradition. While NPD adopts a focused approach to Heimat which focuses solely on immigration, AfD adopts a more nuanced approach which weaves appeals to collective memory with anti-establishment views to justify a wide variety of policies beyond immigration. While AfD does adopt the traditional exclusionary elements of Heimat based on xenophobia, they also frame the idea of protecting "history, cultural, and values" within other contexts including what they refer to as "globalist" and "multicultural" ideologies. Given the fact that AfD's 2017 platform was their first fully-fledged program, this process is not fully fleshed out and is only contained with in a few passages, but they appear to be adopting this approach with respect to a wider range of policies than NPD. There are two key examples in which these types of arguments are made in AfD's 2017 electoral program. The first is an argument with respect to cultural policy which frames multicultural "ideology" as the malicious force from which culture must be preserved:

Nowhere is the [multicultural] ideological influence on the part of the state as strong as in cultural policy. The AfD wants to align cultural policy with technical quality criteria and economic reason instead of political guidelines. Accordingly, the influence of the parties on cultural life must be pushed back while non-profit private cultural foundations and cultural initiatives are strengthened. ${ }^{141}$

AfD often frames "multicultural ideology" as the basis for arguments against immigration but, in this case, they also utilize it to justify a shift towards less state control of culture policy in order to preserve history, culture, and tradition from the influence of ideology. Through an instrumental appeal to collective memory, the state, its cultural policy and its ideological leanings are all framed as the threat to the existing culture. While there is no explicit reference in

${ }^{141}$ AfD 2017, 46-47 
this passage, it highlights the willingness of AfD to expand the utilization of Heimat

argumentation by broadening its appeal to collective memory while effective memory policy.

AfD also utilizes indirect references to history, culture and tradition within the framework of Heimat to justify its Eurosceptic ideas by arguing that that the EU is a threat to the nation-states which are intrinsically connected to history, culture, and tradition:

The EU's claim is restricting or permanently destroying existing democratic nation-states. There are no people within these European states that would be constitutive for such a project, nor is it clear that such a development will take place in the foreseeable future. Cultures, languages, and national identities have come from centuries of historical development. They represent an indispensable identification spaces for their relatives, which can only be effectively implemented in national states with a democratic constitution. Only here can people's sovereignty be lived. ${ }^{142}$

Here, AfD utilizes Heimat to justify their well-documented penchant for Euroscepticism by arguing that the which should not be infringed. In the same way they frame multiculturalism, AfD makes a political argument against EU integration through indirect appeals to collective memory by framing culture, language, and national identity as indispensable parts of nationstate. For AfD, the nation-state is the values of a people's history, culture, and traditions made manifest in the political domain over centuries of historical development. By making a positive argument which frames culture as a key component in the construction of the nation, they frame the EU as an "intruder" who, by attempting to supplant established institutions, is a threat to the culture, history, and traditions of Germany.

\section{Results}

The concept of Heimat originated in FPÖ's electoral programs but, in recent years, has appeared to have been adopted by both NPD and AfD in Germany to varying degrees of success.

${ }^{142}$ AfD 2017, 47-48 
It is important to note that this 'Heimatization' of far-right discourse s also based on collective memory as its exclusionary principles are based on an emotional appeal to the memory of a culture which is perceived to be lost. Moreover, the vast majority of direct and indirect references to history, culture, and tradition are deployed within the conceptual framework of Heimat making it a key component of any attempt to discern the use of history in far-right party programs. With respect to the research question, a thorough analysis of Heimat thus provides significant insight into how references to history, be they direct or indirect, are utilized in farright party programs.

This analysis has produced a number of valuable insights with respect to the goals of the research question. Firstly, it is clear that while direct references to history were a prominent component of far-right electoral platforms in the early 2000s, these types of references have decreased dramatically in favour of more indirect references to history which blur the conceptual lines between culture, history, and tradition or use interchangeable terms such as cultural heritage. So how do these references compare across countries and over time? In general, it appears as though NPD and AfD have adopted many of FPÖ's discursive strategies and argumentation with trends towards the use of indirect references to history and the use of Heimat becoming increasingly prevalent in the programs of both parties, especially in the past five years. AfD adopts FPÖ's tendency to engage in positive framing but places far more emphasis on engaging in nuanced discussions which are more akin to intellectual debate than far-right discourse. Moreover, AfD draw on a more diverse set of historical references evoking grandiose notions about the ancient, medieval, and modern historical achievements of German society. In contrast, FPÖ's arguments are simplistic appeals to collective memory which advocate for the preservation of Austrian culture through positive framing of Austrian culture specifically. AfD 
also utilize direct and indirect references to history much more frequently than FPÖ although this may simply be due to differences in the structure of electoral programs and the tendency for FPÖ to publish supplementary materials which engage in more nuanced discussions on this subject.

NPD adopts FPÖ's basic premise but takes its anti-immigration arguments to the extreme choosing to adopt a model based on negative framework instead of a positive one. They forsake the argumentative technique of promoting the positive aspects German history, culture, and tradition in favour of emphasizing the threats to that culture which NPD argues is massimmigration. This exclusionary argumentation is based on negative framing of history, culture, and tradition and represents an effort to evoke negative emotional responses through an appeal to collective memory. The prominence of anti-immigration rhetoric throughout these platforms also demonstrates that far-right discourse in Germany has embraced the concept of Heimat, a exclusionary nationalistic which argues for the preservation of history, culture, and tradition from foreigners, as part of their argumentation and are actively using its appeal to collective memory. While there is a notable lull in these references between 2009 and 2013, the frequency, magnitude, and urgency of these types of arguments increase significantly in the 2017 platforms of both parties demonstrating the of these arguments in contemporary politics.

In terms of discursive technique and argumentation in a contemporary context, both parties utilize indirect references to history, culture, and tradition through the framework of Heimat but in very different ways. The passages from each party's 2017 electoral programs reveal contrasting approaches in which both parties have adopted varying degrees of Heimat and adjusted their historical references accordingly. NPD appears to have adopted an extremist approach to Heimat which is explicitly exclusionary, xenophobic and racist. It utilizes confrontational language, negative framing of and derogatory language which belittles foreigners 
with very little substantive argumentation. While there are indirect references to culture, they are relatively limited in favour of explicitly exclusionist discourse and utilized primarily to paint Germany as a victim and demonstrate that their history, culture, and traditions are "under attack" due to mass-immigration.

In contrast to NPD's extreme approach to Heimat, AfD's electoral program is based on a moderate approach which utilizes more nuanced argumentation which is more akin to legitimate debate than NPD's rousing call to action. In contrast to NPD's 2017 platform, AfD makes extensive use of indirect references to history, culture, and tradition throughout their electoral program. Their arguments are predicated on the use of positive framing of history often stating the merits of and connecting them to the broader concepts of nationhood, and identity before arguing for their preservation. They justify policy decisions by describing the merits of concepts worth preserving and arguing their status as indispensable parts of society based on history, culture, and tradition. Interestingly, AfD makes use of much more frequent use of direct and indirect references to history than NPD and it seems to be a key component of the framing of their argumentation within the framework of Heimat.

While NPD is more overtly exclusionary and confrontational, especially towards foreigners, AfD rejects this approach and utilizes less confrontational argumentation making seemingly nuanced arguments about the "incompatibility" of certain cultures, with the historically established values of German society. However, AfD's arguments are based primarily on ideological and anti-establishment grounds. They do not explicitly blame the foreigners themselves, but systemic issues based on the ideological orientation of a perceived elite. Moreover, AfD utilizes Heimat to address a wider variety of policies than NPD, broadening 
the argumentative appeal and moderating their exclusionism by supplanting foreigners as the "enemy" and replacing it with ideology. 


\section{VI: Conclusions}

This thesis has explored the relationship between the far-right parties and collective memory through analysis of references to history in far-right party discourse. Through sociological lens of collective memory, the electoral programs of several far-right parties have been examined in order to develop an understanding of the supply-side of party strategy in the context of existing theories on cultural backlash. This chapter refines the results of the preceding analysis and draws conclusions based on the goals of the research question. It consists of a comprehensive review of the findings of the analysis and a discussion of the relevant findings. It

will also discuss potential avenues for future research on far-right parties, far-right discourse, and collective memory within the context of the established set of conclusions.

\section{Assessing the Research Question}

As with any piece of social scientific research, the time has come to reconcile the findings of the analysis with the research question. At the heart of this thesis was one simple question: What happens when the far-right's positive association with history coincides with a problematic past? The difficulty in reconciling implicit concepts like collective memory with the rationalist methodological paradigms of political science made this task anything but straight forward but this thesis chose to adopt an exploratory approach with the goal of establishing research priorities, developed workable definitions and set the stage for the creation of more refined research design. The result is a set of definitive conclusions which produced remarkable insights in the profound shifts in discursive techniques that have occurred among far-right parties in Germany and Austria with respect to collective memory. 
In light of the wide variety of findings, it seems prudent to begin by addressing the research question directly and assessing the validity of the initial hypothesis in order to establish a foundation for further consideration of the conclusions. So, did far-right parties in Germany and Austria shift away from revisionism and towards a reframing strategy for collective memory? With respect to the findings of the analysis, the short answer is, yes. In what is perhaps the most interesting finding of this thesis, the analysis found that direct references to history in far-right electoral programs have decreased in frequency and magnitude across countries and over time while indirect references have increased significantly. This shift away from direct references to history is based on the adoption of reframing discursive strategies which take the emphasis off of direct references to history (including any notion of revisionism) and reframes it ways which are both more palatable to the public and further the nationalist agendas of contemporary far-right parties. In Austria, the normalization of FPÖ within Austrian political institutions has led them to adopt a reframing strategy which reconciles their nationalistic leanings with liberal democratic principles despite controversial comments made by certain groups within their party. This is reflected in their electoral programs the vast majority of which utilize a reframing approach to collective memory with respect to their references to history.

The institutionalization of FPÖ and their widespread adoption of reframing strategies allows Austria to be used as a comparative model for Germany whose lack of institutionalized far-right parties has led to a set of very different trends in discursive strategy. The analysis found that the early electoral programs of far-right parties such as NPD contain a plethora of direct references to history all of which are party of a paradigmatic revisionist strategy with specific policy demands. Over time, however, these references all but disappear in favour of references more in line with the reframing strategy which has been used in Austria. In general, this confirms 
the hypothesis proposed in the introduction to this thesis. Far-right political parties have adopted a reframing approach to historical discourse in countries with problematic pasts and it is worth noting that the use of this strategy is most evident with parties who have been electorally successful such as AfD and FPÖ.

From a discursive perspective, the analysis seems to confirm the vast majority of Ruth Wodak's assertions about the development of contemporary far-right discourse in the years since her original works on far-right discourse. Wodak often argued that far-right parties adopted 'coded' forms of discourse during their shift away from overtly neo-fascist to a 'populist nationalist' strategic model. The analysis clearly demonstrated that overt neo-fascistic references to history largely disappeared from the electoral programs of far-right parties after 2002 and were replaced with appeals to collective memory which blurred the conceptual lines between culture, history, and identity. While there is considerable variation in the strategic usage of these references, the use of 'coded' discourse is a process which has been refined by contemporary farright parties such as AfD who instrumentalize these references by framing them within nuanced arguments for certain policies.

Wodak's assertion that the concept of Heimat would play an increasingly important role far-right discourse proves to be correct, but it appears that it has much greater implications in the far-right politics of other countries than was expected. The prevalence of Heimat in has led to the framing of the vast majority of references to history, culture, and tradition confrontational in nature due to the fact that Heimat frames those concepts as needing to be defended from hostile forces. Moreover, far-right parties tend to frame their culture, history, and tradition in an overly positive light while those of other, unwanted cultures are excluded. Within their electoral platforms, German far-right parties have taken a page from FPÖ and adopted 'coded' forms of 
exclusionism which are presented in the form of simplistic (NPD) or nuanced arguments (AfD) based on the basic principles of Heimat. These parties engage in a form of instrumental presentism by utilizing collective memory to add address the present concerns of the public with immigration, social issues, and multi-culturalism as a whole but take different approaches within the framework of Heimat with one focused on action and the other focused on ideas. In practice, these Heimat-based arguments are instrumentalized to justify exclusionist immigration, refugee, and cultural policies by framing the arguments in a historico-cultural lens which both evokes and emotional response and plays on the present considerations of the public.

While it is abundantly clear that Heimat has been embraced by far-right parties in Germany as part of the transition from revisionism to reframing, the basic practice of reframing history has led to the propagation of other approaches all of which are directed to organize opposition to an external other which is, in this case, immigration by Muslims. With respect to the substance of the historical references, there is a growing focus on historical episodes before the Nazi period in both a direct and indirect manner. For example, early FPÖ electoral programs made references to history which harken back to the achievements of the Austro-Hungarian Empire even going as far as arguing for rights for "historically established" minority groups. In contrast, AfD consistently uses vague references to the "civilizational achievements of Europe" arguing that culture was a crucial component in the development of concepts like democracy, law, and art which must all be defended from encroachment by external others. They also frame this conflict as being civilizational in nature arguing that aspects of European culture are simply incompatible with others and they must be stopped from exerting too much influence on the society of the nation-state. It should be noted that, over time, FPÖ shifted from direct to more 
indirect approach to referencing these historical episodes and it appears that AfD borrowed from this strategy.

Building on the references described above, all of the far-right parties make reference to various forms of legal principles to further their arguments. These include references to the protection of culture in international law, the concept of "human dignity" in German Basic Law and calls for the application of freedom of speech and religion against the perceived repression of culture, history, and tradition by progressives. In a somewhat paradoxical manner, these contemporary far-right parties oppose these ideas when they are used by their opponents yet seem to acknowledge their significance to the public when reframe them to fit their nationalistic narratives. It is interesting to note that far-right often reframes these concepts as "values" that are extensions of the achievements of the nation-state in order to utilize them in a defensive manner for the protection of culture or to emphasize the threat of the external other to the fundamental aspects of liberal democracy.

Finally, there is a growing the tendency for far-right parties in Germany and Austria to conceptualize Europe as a cultural entity and a point of reference for their indirect historical references. Far-right electoral programs are littered with references to Christianity, the Enlightenment, and the "civilizational achievements of Europe" all of which far-right parties seem to construe as the collective accomplishments of a group of nation-states that should serve as a model for the political and cultural structure of the European nations. This is particularly interesting in the context of far-right parties due to their tendency to gravitate towards nationalistic conceptions of history, culture, and tradition. It appears as though the contemporary cultural conflicts and the advent of globalization have, for those who engage in external othering, necessitated the expansion of cultural scope beyond the bounds of single nation-states. 
These new reframing strategies provide some interesting insights into the overarching strategy of far-right in the context of cultural backlash. The consistent use of indirect references to European rather than national history demonstrates the far-right's openness to Europe as a cultural entity but not as a political entity. Moreover, this same concept can be applied to the farright's relationship to liberal constitutional principles and international law many of which they have opposed as "globalist" constructions while to accept as products of the cultural development of their nation states in their electoral programs. The increase in references to liberal democracy among far-right parties over time also seems to represent be a general acceptance that they must, at the very least, maintain the perception that they support liberal democratic principles which is very telling with respect to both the demand-side and supply-side of far-right party politics. Whether this is purely strategic, tied to the specific circumstances of the subject countries, or part of a larger phenomenon within cultural backlash is difficult to say but, given further scholarly attention, these seemingly paradoxical relationships could represent a significant step towards the development of a historico-cultural dimension to cultural backlash particularly with respect to Europe.

As a whole, there is also a of blurring conceptual lines which occurs during the reframing process which appears to be an attempt by far-right parties to subvert the established political, social, and cultural norms in order to establish themselves in positions of political influence where they can legitimize their views. In order to avoid the consequences of talking about history directly, which may inspire accusations of revisionism and more virulent criticism from the opposition, far-right parties combine concepts like history, culture, and tradition together to 'soften' the blow while remaining true to their nationalist messaging. This would explain the recent uptick in references to history, culture, and identity as well as increasing instrumental 
presentism after many years of moderation in far-right electoral platforms. Moreover, it is also possible that the growing cultural divide described by cultural backlash combined with this shift in discursive technique has, in and of itself, played a role in the agglomeration of history, culture, and tradition although the establishment of a causal connection would require further research that is beyond the scope of this thesis.

Aside from the research question, this thesis also focused assessing the value of developing a historical dimension to existing theories of cultural backlash which formed the theoretical basis for this research. After careful consideration, it is the conclusion of this thesis that it is not a historical dimension which should be developed as part of cultural backlash theory but a mnemonic one based on collective memory. It is undoubtable that history, be it directly or indirectly, has played a significant role in far-right discourse there is simply too little substance and too much conceptual overlap to justify a historical dimension in and of itself. As history, culture, and tradition become increasingly interchangeable, it has become clear that the key to understanding the political manifestations of cultural backlash are not based on the substance of their rhetoric but how that rhetoric appeals to the underlying mechanisms of collective memory. Supply-side studies on far-right parties must therefore be predicated on deeper questions: How do we remember? Why do we remember? How do political actors mnemonic mechanisms? It is only by addressing these deeper questions can we begin to understand how the far-right parties utilize history, culture, and tradition in the context of contemporary politics.

As the lines between history, culture, and tradition become increasingly blurred, it is the view of this author that the key to understanding the supply-side of far-right party strategy is not in the substance of their arguments but in how those arguments exploit the mechanisms of memory. Taken together, the sociological literature, discursive studies, and the findings of this 
thesis demonstrate that there is a compelling case to be made for the addition of a mnemonic dimension to existing theories of cultural backlash. Collective memory, despite its failings, is the most promising way forward due to its ability to address the underlying mechanisms of far-right discourse and it should be a key component in future research paradigms for the supply-side of party strategy.

\section{Suggestions for Future Research}

In conclusion, this thesis has explored the references to history in far-right party programs with the goal of establishing the foundation for the development of a historical dimension to existing theories of cultural backlash. While the limitations of the material limited the extent of the findings, it did produce produced a number of key insights by applying the underdeveloped concept of collective memory in the study of far-right parties and their discourse. In accordance with the goals expressed in the introduction of this thesis, these findings provide a number of avenues for future research which will allow for further insight into the historical and mnemonic aspects of far-right parties and their discourse.

After working through the strengths and weaknesses of this thesis, it is clear that there are several aspects of this study which could be improved in future research to provide better results. While the methods were found to be sound, it was, for the most party, the choice of textual materials which was found to be lacking. If any future studies wish to retain the focus on party programs, there are three ways its structure could be changed to improve the findings. First, a more comprehensive analysis could be conducted which adds state and local electoral programs to the body of textual materials in the analysis. While this would open up the study to more external variables and strategic considerations, if they are accounted for, their inclusion could provide a clearer picture, and integrate a regional dimension to the results. Second, adding a 
more diverse range of materials is another option which could provide more detailed results. In the past, many scholars of far-right parties have supplemented electoral programs with other materials such as pamphlets, newspapers, and party advertising to make up for the deficiencies caused by the esoteric and exoteric disjunction which is usually present in the external communications of far-right parties. This could include anything from speeches, media, or political advertising, all of which have already been the subject of extensive research and could provide further insight into the role of history and collective memory in their external communications. Finally, a longer timeline could provide much needed perspective on changes in discursive trends over time, compare changes in ideological orientation, and better account for circumstantial factors all of which would allow for a prospective study to better account for the varying application of collective memory.

The discursive focus of this thesis produced a number of insights which could lead to future research. After observing the effectiveness and potential of utilizing collective memory in a comparative research paradigm for discourse analysis, it is evident that a more concentrated effort to develop a more refined framework for its application to the study of far-right parties. Given the presence of significant substantive links between collective memory, it is likely that a study with the time, materials, and resources could develop a workable framework. While these frameworks would likely struggle to produce causal links due to the nature of collective memory itself, it could provide insight into the cultural and historical aspects of far-right discourse and strategy. With regards to the discourse itself a number of unanswered questions remain. Are there commonalities in discursive techniques across far-right groups? Has the nature of these techniques changed as some groups have become institutionalized members of their party systems? Have some countries become more like others? Furthermore, more work is needed on 
the internal dynamics of collective memory within the parties themselves especially with respect to their ascension to positions of power. Some suggestions include analysis of individuals or groups within each party, party conventions, and internal party documents. The findings of this thesis have also demonstrated that there are discursive insights which could be expanded on by further cross-national comparison of discursive strategy among different far-right groups. It would also be interesting to test the strategic discursive frameworks identified by scholars like Riesigl and Wodak since their ascension to positions of political influence.

Along with the broader implications of this thesis, there are several avenues for further research within the German and Austrian contexts. A more in-depth analysis on the significance of memory culture and discourse across both countries could prove to be interesting if more careful attention is paid to trends in memory culture itself. The results of this study demonstrated that taboos may be working in the official capacity, but these conclusions do not extend beyond that scope. More in-depth analysis with a wider range of materials is required to make substantive conclusions of the state of existing taboos related to memory culture. The concept of Heimat undoubtedly warrants further attention due to its prevalence in far-right discourse and its unique connection to German and Austrian political culture. Despite the prevalence of this concept it is relatively underdeveloped in the context of political discourse and, given more attention, it could provide further insight into the cultural and historical aspects of far-right discourse. There are a number of possible avenues by which this could be accomplished including more comparative analysis, more varied discourse analysis and the development of more rigorous theoretical frameworks. The emergence of Heimat based arguments against cultural, gender, and EU integration policy in AfD's recent electoral programs also requires closer attention with more comprehensive analyses. Most interestingly, scholars could inquire as 
to whether there are similar concepts to Heimat exist in other countries and within other far-right movements allowing for cross-national comparison.

It has often been said that politics is cyclical, and, to some extent, there is a great deal of truth to this statement. Many of the same ideas which contributed to the political upheavals of the twentieth century have crept into the modern political discourse and inspired new forms of far-right radicalism that have rendered storied tools like the political spectrum obsolete. It is tempting to draw comparisons with the past due to the historical connotations of far-right groups, but this always carries the risk of anachronism, a concept which is lost in much of contemporary political discourse. Moreover, in today's volatile political climate such labels have only acted fodder for rabblerousing far-right politicians who often accuse the intellectual "elite" of belittling the concerns of the people. Rhetoric aside, the fact of the matter is that modern iterations of the far-right have been shaped by the profound cultural, political and technological changes of contemporary society and new approaches must be developed to understand them. In these trying times, it is crucial that we understand the pursuit of knowledge must be adaptable, open-minded, and resilient in the face of increasingly radical forms of far-right politics.

This thesis has sought to make a contribution to the development of a new approaches to the study of far-right party discourse by applying the sociological insights of collective memory and connecting it to existing theories of cultural backlash. While the size and scope of this presented its fair share of challenges, the results are promising. This study has demonstrated the scholarly value of studying the supply-side of party strategy, displayed the utility of collective memory as a research paradigm, and produced a wide variety of avenues for further research on the historico-mnemonic aspects of cultural backlash. After reflecting on the results of this thesis, this author can say with confidence that its goals have been achieved and its work complete. 


\section{Bibliography}

Alternative für Deutschland (2017). Wahlprogramm AfD 2017 'Program Für Deutschland' (Election campaign manifesto). Berlin.

Assmann, Jan. Cultural Memory and Early Civilization: Writing, Remembrance, and Political Imagination (Cambridge: Cambridge University Press, 2011)

Bale, Tim. "Supplying the Insatiable Demand: Europe's Populist Radical Right," Government and Opposition 47, Vol. 2 (2012) 256-274

Bar-Tal, Daniel. Intractable Conflicts: Socio-Psychological Foundations and Dynamics (Cambridge: Cambridge University Press, 2013)

Betz, H. G. "The Two Faces of Radical Right-wing Populism in Western Europe," Review of Politics 55, No. 4, 663-685.

Bos, L, van der Brug, W and de Vreese, C.H. "An Experimental Test of the Impact of the Style and Rhetoric on the Perception of Right-Wing Populist and Mainstream Party Leaders," Acta Politica 48, No. 2 (2013) 192-208

Buruma, Ian. The Wages of Guilt: Memories of War in Germany and Japan (New York: New York Review of Books, 2015)

Butler, Thomas. Memory: History, Culture, and the Mind (New York: B. Blackwell, 1989)

Carpentier, Nico and De Cleen, Benjamin. "Bringing Discourse Theory into Media Studies: The Applicability of Discourse Theoretical Analysis (DTA) for the Study of Media Practices and Discourses," Journal of Language and Politics 6, No. 2 (2007) 265-293

Copsey, N. and Richardson, J. E. (eds.) Cultures of post-war British fascism. (New York: Routledge, 2015)

Decker, Frank. “The 'Alternative for Germany' Factors Behind its Emergence and Profile of a New Right-wing Populist Party," German Politics and Society 119, Vol. 34, No.2 (Summer 2016): 1-16

Die Republikaner (2017). Wahlprogramm REP 2017 'Sozial, Patriotisch, Ökologisch' (Election campaign manifesto). Berlin.

Duberman, Martin. The Uncompleted Past (New York: Random House 1969) xii

Eatwell, Roger. "Holocaust Denial: A Study in Propaganda Technique," in Neo-Fascism in Europe eds. L. Cheles, R. Ferguson and M. Vaughan (London: Longman, 1991) 120-146

Eatwell, Roger. "How to Revise History (And Influence People?), Neo-Fascist Style," in The Far Right in Western and Eastern Europe eds. Luciano Cheles, Ronnie Ferguson, and Michalina Vaughan (London: Longman, 1995) 309-326 
Fairclough, Norman "Critical Discourse Analysis as a Method of Social Scientific Research," in Methods of Critical Discourse Analysis ed. Ruth Wodak and Michael Mayer (London: Sage Publications, 2001) 121-138

Freiheitliche Partei Österreich (2017). Wahlprogramm FPÖ 2017 'Österrereicher verdienen FAIRNESS. (Election campaign manifesto). Vienna.

Freiheitliche Partei Österreich (2013). Wahlprogramm FPÖ 2013 'Liebe deine Nächsten. (Election campaign manifesto). Vienna.

Freiheitliche Partei Österreich (2002). Wahlprogramm FPÖ 2002 'Wir gestalten Österreich mit Sicherheit' (Election campaign manifesto). Vienna.

[https://web.archive.org/web/20021130162521/http://www.fpoe.at/bundneu/programm/dafuer_pr ogramm.html]

Fogu, Claudio and Kansteiner, Wulf. "The Politics of Memory and the Poetics of History" in The Politics of Memory in Postwar Europe eds. Richard Lebow, Wulf Kansteiner, and Claudio Fogu (Durham, NC: Duke University Press: 2006) 284-310

Gärtner, Reinhold. "The FPÖ, Foreigners, and Racism in the Haider Era," in The Haider Phenomenon eds. Ruth Wodak and Anton Pelinka (New Brunswick, NJ: Transaction Publishers, 2002)

Halbwachs, Maurice. On Collective Memory. ed. and trans. Lewis Coser. (Chicago: University of Chicago Press, 1992)

Herf, Jeffery. Divided Memory - The Nazi Past in the Two Germanys. (Cambridge: Harvard University Press, 1997)

Hirsch, Herbert. Genocide and the Politics of Memory: Studying Death to Preserve Life. Chapel Hill: University of North Carolina Press, 1995)

Ignazi, P. "The Silent Counter-Revolution: Hypotheses on the Emergence of Extreme Rightwing Parties in Europe," European Journal of Political Research 22, No. 1-2, (1992) 3-34

Inglehart, Ronald. "Changing Values Among Western Publics, 1970-2006: Post-Materialist Values and the Shift from Survival Values to Self-Expression Values," West European Politics 31, No.1-2 (2008): 130-146

Inglehart, Ronald. The Silent Revolution (Princeton: Princeton University Press, 1977)

Inglehart, Ronald and Norris, Pippa. "Trump, Brexit, and the Rise of Populism: Economic Havenots and Cultural Backlash," HKS Faculty Research Working Paper Series, RWP16-026 (August 2016) $1-52$

Kaya, Ayhan and Tecman, Ayşe. "Europe Versus Islam? Right-wing Populist Discourse and the Construction of a Civilizational Identity," The Review of Faith and International Affairs 17, No. 1 (2019) 49-64 
Kitschelt, H. (in collaboration with A. J. McGann) The Radical Right in Western Europe: A Comparative Analysis (Ann Arbor: The University of Michigan Press, 1995)

Krzyżanowski, Michał. "Continuities and Shifts in Recent Discourses and Patterns of Communication of the Freedom Party of Austria (FPÖ)" in Right-Wing Populism in Europe: Politics and Discourse eds. Ruth Wodak, Majid Khosravinik, and Brigitte Mral (London: Bloomsbury Academic, 2013) 135-148

Lakatos, Imre and Alan Musgrave. Criticism and the Growth of Knowledge (Cambridge: Cambridge University Press, 1970)

Langenbacher, Eric and Friederike, Eigler. "Introduction: Memory Boom or Memory Fatigue in $21^{\text {st }}$ Century Germany?” German Politics \& Society 23, No. 3 (76) (2005) 1-5

Levy, Jack. "Case Studies: Types, Designs, and Logics of Inference," Conflict Management and Peace Science Vol. 25, No. 1 (2008) 1-18

Mammone, Andrea. "The Eternal Return? Faux Populism and Contemporarization of NeoFascism Across Britain, Italy and France," Journal of Contemporary European Studies 17, No.2 (2009) 171-192

Markovits, Andrei S. and Reich, Simon. The German Predicament (Ithaca, NY: Cornell University Press, 1997)

Meret, Susi. "The Danish People's Party, the Italian Northern League and the Austrian Freedom Party in a Comparative Perspective: Party Ideology and Electoral Support." PhD diss., SPIRIT PhD Series. 25. University of Aalborg, 2010. ISSN 1903-7783.

Mudde, Cas. The Ideology of the Extreme Right (Manchester: Manchester University Press, 2000)

Mudde, Cas. "The Study of Populist Radical Right Parties: Towards a Fourth Wave" C-REX Working Paper Series, No. 1 (2016) 1-23

Müller, Jan-Werner. Memory and Power in Postwar Europe: Studies in the Presence of the Past (New York: Cambridge University Press, 2002)

Nationaldemokratische Partei Deutschlands (2017). Wahlprogramm NPD 2017 'Heimat Verteidigen' (Election campaign manifesto) Berlin.

Nationaldemokratische Partei Deutschlands (2013). Wahlprogramm NPD 2013 'Natürlich Deutsch' (Election campaign manifesto) Berlin.

Nationaldemokratische Partei Deutschlands (2009). Wahlprogramm NPD 2009 'Deutschlands starke Rechte' (Election campaign manifesto) Berlin. 
Nationaldemokratische Partei Deutschlands (2002). Wahlprogramm NPD 2002 'Ein Programm für das Volk!' (Election campaign manifesto) Berlin.

[http://web.archive.org/web/20020802083135if_/http://www.npd.net:80/]

Riesigl, Martin. "The Discourse-Historical Approach," The Routledge Handbook of Critical Discourse Studies eds. John Flowerdew and John E. Richardson (London: Routledge, 2017) 4459

Reisigl, Martin. "The Dynamics of Right-wing Populist Argumentation in Austria" in F. H. van Eeemeren, J. A. Blair, C. A. Willard and B. Garssen (eds.), Proceedings of the Sixth Conference of the International Society for the Study of Argumentation (2007) 1127-1134

Reisigl, Martin and Wodak, Ruth. Discourse and Discrimination: The Rhetoric of Racism and Anti-Semitism (London: Routledge, 2001)

Reisigl, Martin and Wodak, Ruth. Discourse and Discrimination: the Rhetoric of Racism and Anti-Semitism (London: Routledge, 2001)

Roediger Henry and Magdalena Abel "Collective memory: A New Arena of Cognitive Study". Trends in Cognitive Sciences. Vol. 19, No.7 (July 2015) 359-361

Rooduijn, Matthijs and Pauwel, Teun. "Measuring Populism: Comparing Two Methods of Content Analysis," West European Politics 34, No. 6 (2011): 1272-1283

Salzborn, Samuel. "Renaissance of the New Right in Germany? A Discussion of New Right Elements in German Right-wing Extremism Today," German Politics and Society 119, Vol. 34, No. 2 (Summer 2016): 36-63

Smith, Anthony D. Myths and Memories of a Nation (Oxford: Oxford University Press, 1999)

Spiegel, Gabrielle M. Stories of Peoplehood: The Politics and Morals of Political Membership (New York: Cambridge University Press, 2003)

van Kessel, Stijn. Populist Parties in Europe: Agents of Discontent? (London: Palgrave MacMillan, 2015) 61-62

Verovšek, Peter J. "Collective Memory, Politics, and the Influence of the Past: The Politics of Memory as a Research Paradigm," Politics, Groups, and Identities, Vol. 3 No. 3 (2016) 529-543

Wang, Zheng. Memory Politics, Identity, and Conflict: Historical Memory as a Variable (London: Palgrave MacMillan, 2018)

Weedon, Chris and Jordan, Glenn. "Collective Memory: Theory and Politics," Social Semiotics Vol. 22, No.2 (April 2012) 143-153

Wertsch, James V. and Henry L. Roediger III. "Collective Memory: Conceptual Foundations and Theoretical Approaches,” Memory 16, No. 3 (2008) 318-326 
Wodak, Ruth. "Anything Goes!" - The Haiderization of Europe" in Right-Wing Populism in Europe: Politics and Discourse eds. Ruth Wodak, Majid Khosravinik, and Brigitte Mral (London: Bloomsbury Academic, 2013) 23-38

Wodak, Ruth. The Politics of Fear: What Right-wing Discourses Mean. (London: Sage, 2015)

Wodak, Ruth and Forchtner, Bernhard. "Embattled Vienna 1683/2010: Right-wing Populism, Collective memory and the Fictionalisation of Politics," Visual Communication 13, No. 2 (2014) 231-255

Wodak, R. and Richardson, J. E. (eds.) Analysing Fascist Discourse: European Fascism in Talk and Text (London: Routledge, 2013)

Wüstenberg, Jenny and Art, David. "Using the Past in the Nazi Successor States from 1945 to the Present," The Annals of the American Academy of Political and Social Science 617, No. 1 (2008) $72-87$ 